Check for updates

Cite this: Dalton Trans., 2020, 49, 322

Received 17th October 2019, Accepted 19th November 2019

DOI: 10.1039/c9dt04062e

rsc.li/dalton

\title{
Neutral, cationic and anionic organonickel and -palladium complexes supported by iminophosphine/phosphinoenaminato ligands $\uparrow+$
}

\author{
Tomás G. Santiago, (D) Carmen Urbaneja, Eleuterio Álvarez, (D) Elena Ávila, \\ Pilar Palma (iD) and Juan Cámpora (iD *
}

\begin{abstract}
We report a series of organometallic nickel and palladium complexes containing iminophosphine ligands $\mathrm{R}_{2} \mathrm{PCH}_{2} \mathrm{C}(\mathrm{Ph})=\mathrm{N}$-Dipp (Dipp = 2,6-diisopropylphenyl; $\mathrm{R}=\mathrm{iPr}, \mathrm{La} ; \mathrm{R}=\mathrm{Ph}, \mathrm{Lb}$; and $\mathrm{R}=0-\mathrm{C}_{6} \mathrm{H}_{4} \mathrm{OMe}, \mathrm{Lc}$ ), synthesized by ligand exchange or oxidative addition reactions, and we investigate the capacity of such ligands to undergo reversible deprotonation to the corresponding phosphinoenaminato species. In the attempted ligand exchange reaction of the nickel bis(trimethylsilyl)methyl precursor $\left[\mathrm{Ni}_{(}\left(\mathrm{CH}_{2} \mathrm{SiMe}_{3}\right)_{2} \mathrm{Py}_{2}\right]$ with $\mathbf{L b}$, the iminophosphine acts as a weak acid rather than a neutral ligand, cleaving one of the $\mathrm{Ni}-\mathrm{C}$ bonds, to afford the phosphinoenaminato complex $\left[\mathrm{Ni}_{(}\left(\mathrm{CH}_{2} \mathrm{SiMe}\right)(\mathbf{L} \mathbf{b} \mathbf{b})(\mathrm{Py})\right]\left(\mathbf{L}^{\prime} \mathbf{b}=\right.$ conjugate base of $\left.\mathbf{L b}\right)$. We disclose a general method for the syntheses of complexes $\left[\mathrm{Ni}_{(}\left(\mathrm{CH}_{2} \mathrm{SiMe}_{3}\right)(\mathbf{L})(\mathrm{Py})\right]^{+}(\mathbf{L}=\mathbf{L a}$, $\mathbf{L b}$ or $\mathbf{L c})$, and demonstrate that iminophosphine deprotonation is a general feature and occurs reversibly in the coordination sphere of the metal. By studying proton exchange reactions of the cation $\left[\mathrm{Ni}_{(}\left(\mathrm{CH}_{2} \mathrm{SiMe}\right)(\mathbf{L b})\right.$ $(\mathrm{Py})]^{+}$with bases of different strength we show that the conjugate phosphinoenaminato ligand in $\left[\mathrm{Ni}\left(\mathrm{CH}_{2} \mathrm{SiMe}_{3}\right)\left(\mathrm{L}^{\prime} \mathbf{b}\right)(\mathrm{Py})\right]$ is a base with strength comparable to DBU in THF. The acyl group in the functionalized aryl complex $\left[\mathrm{Ni}\left(p-\mathrm{C}_{6} \mathrm{H}_{4} \mathrm{COCH}_{3}\right)(\mathrm{Br})(\mathrm{La})\right]$ does not interfere in the iminophosphine deprotonation with $\mathrm{NaH}$. The latter reaction affords the unusual anionic hydroxide species $\left[\mathrm{Ni}\left(p-\mathrm{C}_{6} \mathrm{H}_{4} \mathrm{COCH}\right)(\mathrm{OH})\left(\mathrm{L}^{\prime} a\right)\right]^{-} \mathrm{Na}^{+}$, which was isolated and fully characterized.
\end{abstract}

\section{Introduction}

Iminophosphines are very attractive ligands used in the development of new homogeneous catalysts for various processes, ${ }^{1}$ because their modular design ${ }^{2}$ allows systematic and independent variation of the steric and electronic properties of the $\mathrm{P}$ and $\mathrm{N}$ donor centers, and the structural properties of the ligand backbone. Among the most typical examples of this class of hybrid ligands are iminophosphines with a single carbon spacer connecting the phosphine and imino functionalities. ${ }^{3,4}$ Such iminophosphine ligands often bear bulky $o, o^{\prime}$-disubstituted $N$-aryl substituent groups, like the species A shown in Scheme 1. This substitution pattern is a common feature in many types of catalysts, particularly in those used for late transition metal olefin poylmerization. ${ }^{5}$ In

Instituto de Investigaciones Quimicas, CSIC-Universidad de Sevilla. CIC-Cartuja, c/Américo Vespucio, 49, 41092 Sevilla, Spain.E-mail: campora@iiq.csic.es $\dagger$ Dedicated to the memory of Prof. Richard A. Andersen.

\$Electronic supplementary information (ESI) available: Complete experimental details, spectroscopic and crystallographic data; CIF files for compounds CCDC 1944621 (3b), 1944622 (4c), 1944623 (6b), 1944624 (7b) and 1944625 (16). For ESI and crystallographic data in CIF or other electronic format see DOI: 10.1039/ C9DT04062E these catalysts, the $o, o^{\prime}$ aryl groups control the molecular weights of the products. ${ }^{6}$ Not surprisingly, nickel and palladium iminophosphine complexes have attracted attention as ethylene polymerization or oligomerization catalysts but unfortunately, their activities are significantly lower than those of the well-known $\alpha$-diimine catalysts, and their products tend to exhibit broad or bimodal molecular weight distributions. ${ }^{7,8}$ One of the potential problems identified in hybrid iminophosphine catalyst systems is the weakly acidic character of the hydrogen atoms in the iminophosphine backbone. As shown in Scheme 1, iminophosphine complexes are deprotonated by strong bases to afford phosphinoenaminates. ${ }^{9}$ Therefore, it was suggested that polymerization catalysts using this type of ligand could be also deprotonated by aluminum alkyls used as

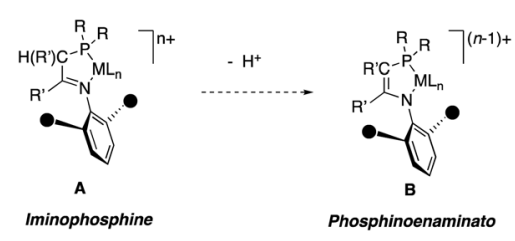

Scheme 1 The relationship between iminophosphine and phosphinoenaminato complexes. 
co-catalysts, turning the active species into more electron-rich phosphinoenaminate species (shown as $\mathbf{B}$ in Scheme 1). ${ }^{8}$ However, the weak Brønsted acidity of iminophosphine ligands could be turned into an advantage for other applications. In recent years, there has been growing interest in ligand-metal cooperative behaviour as an alternative strategy to extend or improve the capacities of metals in catalysis. ${ }^{10}$ Among the various sorts of metal-ligand cooperation, reversible ligand protonation/deprotonation is a central step in some important processes involving hydrogen transfer reactions, such as transfer hydrogenation, ${ }^{11}$ or aerobic oxidations. ${ }^{10 a}$ This context has brought some enolizable ligands such as bis(phosphinomethyl)pyridine (PNP) pincers, closely related to iminophosphines, under the spotlight. ${ }^{10 b, e}$ Although enolizable iminophosphine chelates have been less extensively investigated in this regard, Fryzuk has recently demonstrated their ability to promote hydrogen activation through metal-ligand cooperative behaviour in Ir and Ru complexes. ${ }^{12}$ In addition, first-row transition metal complexes with deprotonated phosphinoamidinates, iminophosphine-type ligands, have found many useful applications in catalysis. ${ }^{13}$ These reports suggest that iminophosphines could also induce similar cooperative phenomena when coordinated to $16 \mathrm{e}$, square-planar complexes of $\mathrm{Ni}$, enhancing $\mathrm{H}$-transfer reactions that are usually facile in the chemistry of the heavier group 10 metals, particularly Pd.

One of our current interests focuses on the ability of $\mathrm{Ni}$ complexes to emulate $\mathrm{Pd}$ in fundamental processes that are relevant to catalysis. Whereas a number of organometallic complexes of the heavier group 10 elements (Pd and Pt) supported by deprotonable iminophosphine ligands have been reported, the chemistry of their analogues was examined in less detail. ${ }^{9}$ Some years ago, we reported a series of Ni and Pd complexes containing non-enolizable iminophosphinite hybrid ligands, ${ }^{14}$ similar to iminophosphines, except that the linker between the $\mathrm{PR}_{2}$ unit and the imino group is an oxygen atom. These are excellent ligands for both $\mathrm{Ni}$ and $\mathrm{Pd}$ organometallic complexes. This prompted us to develop pathways to well-defined organometallic derivatives of Ni ligated by weakly acidic iminophosphines, and to compare these Ni derivatives to their Pd counterparts. Herein we report our initial results on this topic, including the synthesis of organometallic species supported by three bulky iminophosphine ligands, and for the first time we illustrate reversible iminophosphine deprotonation chemistry on the coordination sphere of Ni(II).

\section{Results and discussion}

\section{Iminophosphine ligands}

In this study, we chose to focus on the iminophosphine ligands La, Lb and Lc, with an enolizable skeleton based on acetophenone-imine, and differing only in the $\mathrm{PR}_{2}$ fragment ( $\mathrm{R}=i$-propyl, phenyl or 2 -anisyl, respectively). Such ligands are readily obtained using a one-pot procedure that involves sequential deprotonation of the acetophenone imine, and elec-

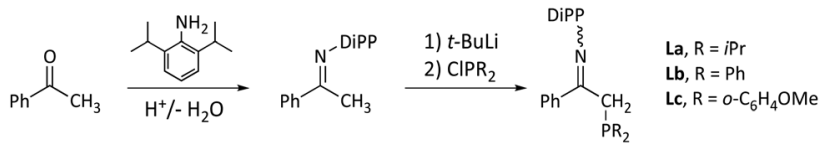

Scheme 2 Syntheses of iminophosphine ligands.

trophilic phosphination of the enaminate anion with the corresponding chlorophosphine (Scheme 2). Ligand Lb has been reported in the literature before. ${ }^{9 b}$ Deprotonation of acetophenone imines is usually accomplished with lithium diisopropylamide (LDA), but we found that the same can be conveniently achieved using one equivalent of $t$-BuLi at $-80^{\circ} \mathrm{C}$, avoiding the need to generate the lithium amide. The ligands were separated from lithium chloride by extraction in hexane. $\mathbf{L a}$ and $\mathbf{L b}$ are obtained as pale-yellow oils, but Lc is obtained as a yellow solid that is easier to handle and store. The NMR spectra of all three ligands show that these exist as mixtures of cis/trans isomers, with no detectable amounts of enamine tautomers.

\section{Ligand exchange reactions}

Methods for the synthesis of organometallic derivatives of ligands containing active (acidic) $\mathrm{CH}_{n}$ groups usually avoid transmetallation reactions with organolithium or organomagnesium reagents, as these behave as strong bases susceptible to deprotonation of the coordinated ligand. Instead, ligand exchange reactions are usually preferred for this purpose. ${ }^{15}$ In our previous study, we found that pyridine-stabilized nickel dialkyls, as well as equivalent pyridine or COD-bearing dialkyl and metallacyclic palladium complexes, are very convenient precursors that provide access to a plethora of organometallic derivatives via exchange reactions. ${ }^{16}$ Since (trialkylsilyl)methyl derivatives often exhibit enhanced stability compared with "normal" alkyl derivatives, we set to synthesize a series of bis (trimethylsilyl)methyl derivatives of $\mathrm{Ni}$ and $\mathrm{Pd}$, starting out from the precursor complexes $\left[\mathrm{Ni}\left(\mathrm{CH}_{2} \mathrm{SiMe}_{3}\right)_{2}(\mathrm{Py})_{2}\right]^{17 a}(\mathbf{1})$ and $\left[\mathrm{Pd}\left(\mathrm{CH}_{2} \mathrm{SiMe}_{3}\right)_{2}(\mathrm{COD})\right]^{17 b}$ (2), respectively. Interestingly, the reactions of these nickel and palladium precursors with ligands La, Lb and Lc had divergent results (Scheme 3).

As discussed below in more detail, the reactions of precursor 1 with La-Lc fail to produce the expected dialkylnickel derivatives. Only in the case of $\mathbf{L b}$, a different type of product (3b, Scheme 3 and Fig. 1) could be isolated after the reaction mixture was allowed to evolve for $20 \mathrm{~h}$ at room temperature. In contrast, the exchange reactions of the iminophosphine ligands with the Pd precursor 2 proceed as expected affording the corresponding dialkyls $\mathbf{4 a - c}$, which were successfully isolated as dark brown solids. Although essentially quantitative conversions were observed in the NMR spectra of the crude reaction mixtures, the high solubility of the products in hydrocarbon solvents (particularly 4a), combined with some thermal instability in solution, hampered their crystallization, thus reducing their final isolated yields. The dialkyl derivative 4c is thermally more stable and quality crystals suitable for $\mathrm{X}$-ray diffraction could be grown; its crystal structure is shown 
1
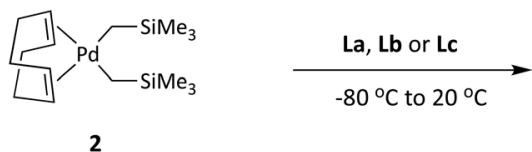

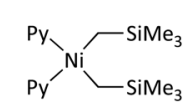

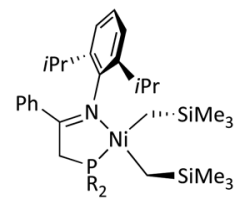

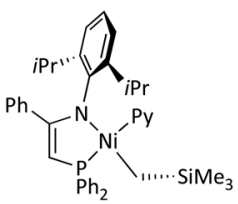

3b

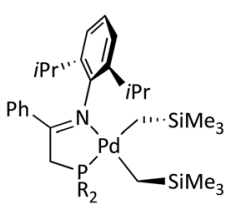

$4 a-c$
Scheme 3 Divergent reactivity of precursors 1 and 2 with iminophosphine ligands.

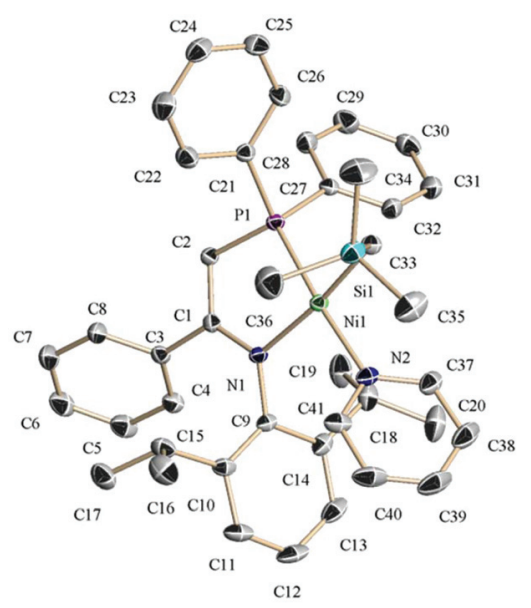

Fig. 1 The crystal structure of $3 \mathrm{~b}$ with $50 \%$ probability thermal ellipsoids. The selected bond distances $(\AA \AA)$ and angles $\left({ }^{\circ}\right)$ : $\mathrm{Ni}(1)-C(33)$, $1.9593(13) ; \mathrm{Ni}(1)-\mathrm{P}(1), 2.1153(4) ; \mathrm{Ni}(1)-\mathrm{N}(1), 2.0015(11) ; \mathrm{Ni}(1)-\mathrm{N}(2)$, 1.9552(11); $C(1)-N(1), 1.3530(16) ; C(1)-C(2), 1.3842(17) ; C(33)-N i(1)-$ $\mathrm{N}(2)$, 89.91(5); and $\mathrm{P}(1)-\mathrm{Ni}(1)-\mathrm{N}(1), 85.33(3)$; torsion $\mathrm{N}(1)-\mathrm{C}(1)-\mathrm{C}(2)-$ $P(1), 5.76(17)$; dihedral between DiPP ring and plane $N(1) C(1) N i(1), 68.4$; dihedral between $\mathrm{Ph}$ ring and plane $\mathrm{C}(1) \mathrm{N}(1) \mathrm{C}(2), 46.2$; and dihedral between planes $\mathrm{Ni}(1) \mathrm{C}(33) \mathrm{N}(2)$ and $\mathrm{Ni}(1) \mathrm{N}(1) \mathrm{P}(1), 6.4$.

in Fig. 2. The crystal structures of simple Pd(II) dialkyls are not particularly frequent, and the CSD database only contains a couple of examples stabilized with hybrid P,N donors. ${ }^{9 a, 18}$ As expected, the stronger trans influence of the $\mathrm{P}$ atom is reflected in a significant lengthening of the Pd-C39 bond with regard to the bond in trans to the nitrogen (2.103(6) vs. 2.046(6) ̊). The concurrent trans effect could be translated into a significant kinetic labilization of the alkyl sitting in trans to the P donor.

As mentioned above, the reaction of the nickel dialkyl precursor with iminophosphines La-Lc follows an unexpected

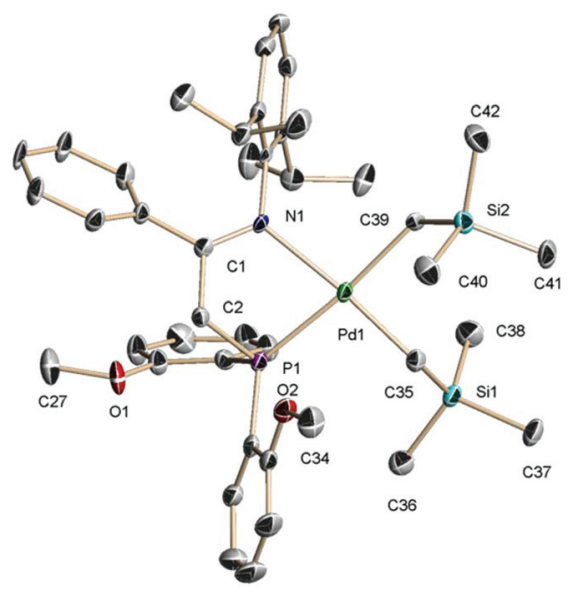

Fig. 2 The crystal structure of $4 \mathrm{c}$ with $50 \%$ probability thermal ellipsoids. The selected bond distances ( $\AA$ ) and angles $\left({ }^{\circ}\right)$ : $\mathrm{Pd}(1)-C(35), 2.046(6)$; $\mathrm{Pd}(1)-\mathrm{C}(39), 2.103(6) ; \mathrm{Pd}(1)-\mathrm{N}(1), 2.235(5) ; \mathrm{Pd}(1)-\mathrm{P}(1), 2.3017(17) ; \mathrm{C}(1)-\mathrm{N}(1)$, 1.301(8); $C(1)-C(2), 1.505(8) ; C(35)-P d(1)-C(39), 88.0(3)$; and $P(1)-$ $\mathrm{Pd}(1)-\mathrm{N}(1)$, 78.50(14); torsion $\mathrm{N}(1)=\mathrm{C}(1)-\mathrm{C}(2)-\mathrm{P}(1), 41.3(7)$; dihedral between DiPP ring and plane $\mathrm{N}(1) \mathrm{C}(1) \mathrm{Pd}(1), 71.0$; dihedral between $\mathrm{Ph}$ ring and plane $\mathrm{C}(1) \mathrm{N}(1) \mathrm{C}(2), 44.5$; and dihedral between planes $\mathrm{Pd}(1) \mathrm{C}(35) \mathrm{C}(39)$ and $\mathrm{Pd}(1) \mathrm{N}(1) \mathrm{P}(1), 4.9$.

course. ${ }^{31} \mathrm{P}\left\{{ }^{1} \mathrm{H}\right\}$ NMR monitoring showed that the reactions initially afford mixtures of several P-containing species that slowly evolve over a time lapse of $c a$. one day. Only for $\mathbf{L b}$ the ${ }^{31} \mathrm{P}\left\{{ }^{1} \mathrm{H}\right\}$ spectra of the reaction mixture gradually simplified into a single P-containing species that was eventually isolated and identified as the monoalkylnickel phosphinoenaminate complex $\mathbf{3 b}$. The identity of $\mathbf{3 b}$ was confirmed by its crystal structure shown in Fig. 1. The molecule exhibits a single alkyl ligand that, as deduced from the solution NMR data, is placed in cis to the $\mathrm{P}$ donor, while the pyridine unit occupies the trans position. The anionic phosphinoenaminate ligand is almost planar $\left(\mathrm{N}-\mathrm{C}=\mathrm{C}-\mathrm{P}\right.$, dihedral $\left.=5.6^{\circ}\right)$ and the chelate lacks the characteristic puckering observed in the structure of 4c. The flat geometry of the chelate ring and the C1-C2 and C1-N1 bond lengths within (ca. 1.38 and $1.35 \AA$, respectively) are typical of a delocalized enamine-type system.

The complex outcome of the reactions of the dialkyl 1 with iminophosphine ligands was not entirely unexpected. In previous research we found that, whilst exchange reactions of pyridine-stabilized dialkyls $\left[\mathrm{MR}_{2} \mathrm{Py}_{2}\right](\mathrm{M}=\mathrm{Ni}$ and $\mathrm{Pd}$; and $\mathrm{R}=\mathrm{Me}$, $\mathrm{CH}_{2} \mathrm{Ph}, \mathrm{CH}_{2} \mathrm{SiMe}_{3}$, etc.) with various $\mathrm{N}, \mathrm{N}$ bidentate donors were in general clean and quantitative, the reaction of 1 with the bulky $\alpha$-diimine ligand $\mathrm{MeC}(=\mathrm{N}$-DiPP $)-\mathrm{C}(=\mathrm{N}$-DiPP $) \mathrm{CMe}$ (DiPP = 2,6-diisopropylphenyl) was incomplete, which we attributed to the steric crowding when two $\mathrm{CH}_{2} \mathrm{SiMe}_{3}$ groups are simultaneously attached to the relatively small $\mathrm{Ni}$ atom. ${ }^{16}$ Very likely, the reaction of $\mathbf{1}$ with bulky iminophosphines is also sterically disfavored. This allows that a slow but irreversible process like proteolytic cleavage of a $\mathrm{Ni}-\mathrm{C}$ bond by the acidic ligand may become competitive, this being selective only in the case of $\mathbf{3 b}$. Nevertheless, the successful isolation of the latter as a stable complex inspired us to achieve the goal of 
synthesizing its analogues with ligands L'a (3a) and L'c (3c). To this end, we devised a general strategy that would begin with the syntheses of cationic iminophosphine monoalkyl-pyridine derivatives $\left[\mathrm{Ni}\left(\mathrm{CH}_{2} \mathrm{SiMe}_{3}\right)(\mathbf{L})(\mathrm{Py})\right]^{+}(\mathbf{L}=\mathbf{L a}, \mathbf{L b}$ or $\mathbf{L c})$, followed by the removal of one of the weakly acidic $\mathrm{H}$ protons from L with a strong base, as reported by Green and Pascu for several Pd and Pt complexes. ${ }^{9}$ To prepare the desired cationic precursors, we initially considered the reaction of $\mathbf{1}$ with the conjugate acid of the corresponding ligand, i.e., $\mathrm{HL}^{+}$. Disappointingly, attempts to generate the triflate salt $[\mathbf{H L b}]^{+} \mathrm{OTf}^{-}$from Lb and one equivalent of trifluoromethanesulfonic (triflic) acid led to decomposition and a phosphorusfree product was obtained instead, presumably the iminium salt $[\mathrm{PhC}(=\mathrm{NHDiPP}) \mathrm{Me}]^{+} \mathrm{OTf}^{-}$. Consequently, we adopted the alternative plan depicted in Scheme 4. Its key feature is a less hindered alkylnickel precursor complex: the tris-pyridine monoalkyl cation 5. It is worth mentioning that no $\mathrm{Ni}$ (II) monoalkyl species ligated uniquely by pyridine co-ligands has been reported to date. As shown in Scheme 4, this compound is accessible by reacting 1 with one equivalent of pyridinium triflate. Complex 5 can be isolated in high yield as an analytically pure greenish-yellow solid and, in contrast to the parent dialkyl 1, it is fairly stable in dichloromethane solution. Its ${ }^{1} \mathrm{H}$ NMR and ${ }^{19} \mathrm{~F}$ spectra show broad signals at room temperature, which is consistent with rapid exchange with the labile pyridine in trans to the alkyl, while the pair of ligands in the cis position are static, or exchange at a much slower rate. The lability of the pyridine ligand was also noticed in the ESI-MS spectrum of this compound, which only shows a faint molecular ion signal $\left(\left[\mathrm{Ni}\left(\mathrm{CH}_{2} \mathrm{SiMe}_{3}\right) \mathrm{Py}_{3}\right]^{+}, m / z=382.1\right)$, and two much stronger signals corresponding to the loss of one and two pyridine ligands $\left(\left[\mathrm{Ni}\left(\mathrm{CH}_{2} \mathrm{SiMe}_{3}\right) \mathrm{Py}_{2}\right]^{+}\right.$and $\left[\mathrm{Ni}\left(\mathrm{CH}_{2} \mathrm{SiMe}_{3}\right) \mathrm{Py}\right]^{+}, m / z=$ 303.1 and 224.1, respectively), with correct isotope peak distributions.

As shown in Scheme 4, complex 5 reacts with one equivalent of either $\mathbf{L a}, \mathbf{L b}$ or Lc, cleanly affording the corres-

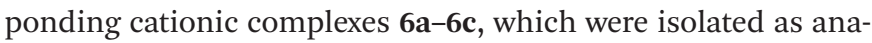
lytically pure products and fully characterized. Their NMR spectra showed that they exist in a single geometric configuration, except $\mathbf{6 c}$ that was obtained as a mixture of $\mathrm{P}, \mathrm{C}$ cis
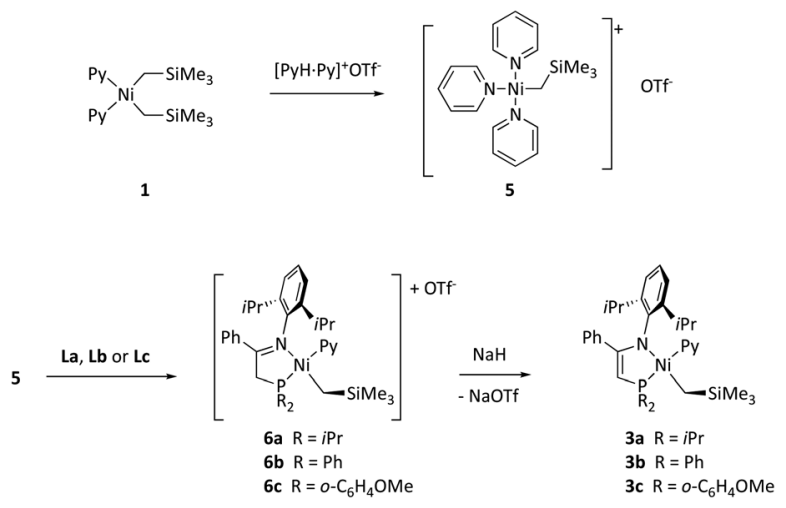

Scheme 4 General approach to the syntheses of nickel phosphinoenaminate complexes.

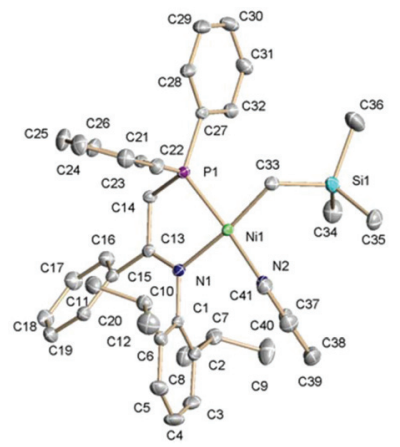

Fig. 3 The crystal structure of $6 \mathrm{~b}$ with $50 \%$ probability thermal ellipsoids. The selected bond distances $(\AA)$ and angles $\left({ }^{\circ}\right)$ : $\mathrm{Ni}(1)-\mathrm{C}(33)$, 1.9512(17); $\mathrm{Ni}(1)-\mathrm{P}(1), 2.0943(4) ; \mathrm{Ni}(1)-\mathrm{N}(1), 2.0329(13) ; \mathrm{Ni}(1)-\mathrm{N}(2)$, 1.9572(13); $\mathrm{C}(13)-\mathrm{N}(1), 1.298(2) ; \mathrm{C}(13)-\mathrm{C}(14), 1.510(2) ; \mathrm{C}(33)-\mathrm{Ni}(1)-\mathrm{N}(2)$, 90.48(6); and $\mathrm{P}(1)-\mathrm{Ni}(1)-\mathrm{N}(1)$, 84.26(4); torsion $\mathrm{N}(1)-\mathrm{C}(13)-\mathrm{C}(14)-\mathrm{P}(1)$, 16.53(17); dihedral between DiPP ring and plane $\mathrm{N}(1) \mathrm{C}(13) \mathrm{Ni}(1), 72.2$; dihedral between $\mathrm{Ph}$ and plane $\mathrm{C}(13) \mathrm{N}(1) \mathrm{C}(14), 41.6$; and dihedral between planes $\mathrm{Ni}(1) \mathrm{C}(33) \mathrm{N}(2)$ and $\mathrm{Ni}(1) \mathrm{N}(1) \mathrm{P}(1), 12.8$.

(major) and trans (minor) isomers. The crystal structure of $\mathbf{6 b}$ was determined (Fig. 3) for comparison with its neutral analogue 3b. Except for the logical differences within the phosphinoenaminate/iminophosphine systems, the structures of $\mathbf{6 b}$ and 3b show a remarkable similarity, both providing nearly identical coordination environments of the Ni(II) center. Thus, albeit the overall positive charge would be expected to strengthen metal-ligand interactions in the cationic derivative, both $\mathrm{Ni}-\mathrm{N}$ bonds are marginally longer in the cation $\mathbf{6 b}$ than in neutral $\mathbf{3 b}$, whilst both $\mathrm{Ni}-\mathrm{C}$ distances are nearly the same. Only the dative Ni-P bond exhibits a slight shortening in $\mathbf{6 b}$, and both complexes exhibit a similar degree of tetrahedral distortion at the Ni center. The similarity of the coordination sphere of $\mathrm{Ni}$ in the cationic and neutral complexes suggests that the influence of the protonated/deprotonated state of the $\mathrm{P}-\mathrm{N}$ unit is mostly limited to the PN ligand, and has only a minor influence on the electronic state of the metal atom.

A suspension of solid $\mathrm{NaH}$ in THF deprotonates complexes 6a-c, cleanly affording the corresponding phosphinoenaminates $\mathbf{3 a - c}$. The heterogeneous reaction is slow and takes several hours to complete. However, it is also very selective, cleanly affording a single product in each case, even if the cationic precursor (6c) existed as a cis/trans mixture. In addition, we also investigated the deprotonation of $\mathbf{6 b}$ with a set of bases of different strength (see the last point in this section, "reversibility of acid-base reactions"). The spectra of $\mathbf{3 b}$ obtained by this method are undistinguishable from those of the sample isolated from the reaction of $\mathbf{1}$ with $\mathbf{L b}$.

\section{Oxidative addition of aryl halides to zero-valent Ni and Pd iminophosphine species}

Oxidative addition of aryl halides and sulfonates to $\mathrm{Ni}(0)$ and $\operatorname{Pd}(0)$ complexes is a key step in many catalytic reactions leading to $\mathrm{C}-\mathrm{C}$ or $\mathrm{C}$-heteroatom bond formation. Although a large number of $\mathrm{Ni}(\mathrm{II})$ and $\mathrm{Pd}(\mathrm{II})$ aryl complexes containing various ligands (phosphine, $\mathrm{N}$-heterocyclic carbenes, etc.) have 
been synthesized by oxidative addition reactions, this type of reaction has been rarely used with iminophosphines. ${ }^{19-21}$ In the case of Ni complexes, the availability of convenient sources of $\mathrm{Ni}(0)$ such as $\mathrm{Ni}(\mathrm{COD})_{2}$ considerably facilitates the generation of zero-valent precursors. The oxidative addition of stabilized phosphonium ylides has been used to prepare phenyl-nickel enaminate complexes. ${ }^{19}$ However, to the best of our knowledge, the oxidative addition of aryl halides or sulfonates to $\mathrm{Ni}(0)$-iminophosphine complexes has not been hitherto demonstrated. Several examples of this type of reaction involving $\operatorname{Pd}(0)$ have been reported, using either $\operatorname{Pd}(\mathrm{DBA})_{2}$ (DBA = dibenzylideneacetone $)$ in the presence of the iminophosphine ligand $^{20}$ or pre-formed $\operatorname{Pd}(0)$ species. $^{21}$ However, these methodologies are usually complicated by the difficulty of removing DBA. In recent years, complex 2 has been used as a versatile source of $\operatorname{Pd}(0)$, much as a synthetic equivalent of $\mathrm{Ni}(\mathrm{COD})_{2}$, without the practical drawbacks of DBA complexes. $^{22}$ Considering these antecedents, we deemed it useful to check whether iminophosphines La-Lc are competent ligands to support oxidative addition reactions leading to stable organometallic complexes of both Ni and Pd.

We first investigated the oxidative addition of 4-acetylphenyl halides or triflate, $p$ - $\mathrm{AcOC}_{6} \mathrm{H}_{4} \mathrm{X}(\mathrm{X}=\mathrm{Br}, \mathrm{Cl}$ and OTf $)$, to $\mathrm{Ni}(0)$. Preliminary studies showed that iminophosphines La-Lc interact only weakly with $\mathrm{Ni}(\mathrm{COD})_{2}$ in THF at room temperature, forming blue coloured solutions whose ${ }^{31} \mathrm{P}\left\{{ }^{1} \mathrm{H}\right\}$ NMR spectra indicate the presence of substantial amounts of free ligands. Therefore, we combined equimolar amounts of $\mathrm{Ni}(\mathrm{COD})_{2}$, ligand (La, Lb or $\left.\mathbf{L c}\right)$ and the corresponding aryl halide/triflate in THF at low temperatures $\left(-80^{\circ} \mathrm{C}\right)$, and then allowed the mixtures to react at room temperature (Scheme 5). Upon warming, the solutions become dark brown, evolving to somewhat clearer brownish-orange tones within 60-90 min. The ${ }^{31} \mathrm{P}\left\{{ }^{1} \mathrm{H}\right\}$ NMR spectra of the reaction mixtures indicate that oxidative additions proceed cleanly for $\mathrm{X}=\mathrm{Br}$ or $\mathrm{Cl}$, affording in each case a single P-containing species. A workup of these solutions affords the corresponding oxidative addition products as yellow solids in good yields. The spectroscopic properties of these complexes are fully consistent with their expected geometries, with their NMR spectra showing that the functionalized 4-acetylphenyl fragment is incorporated into the Ni(II) complex and is placed in cis to the phosphine donor.

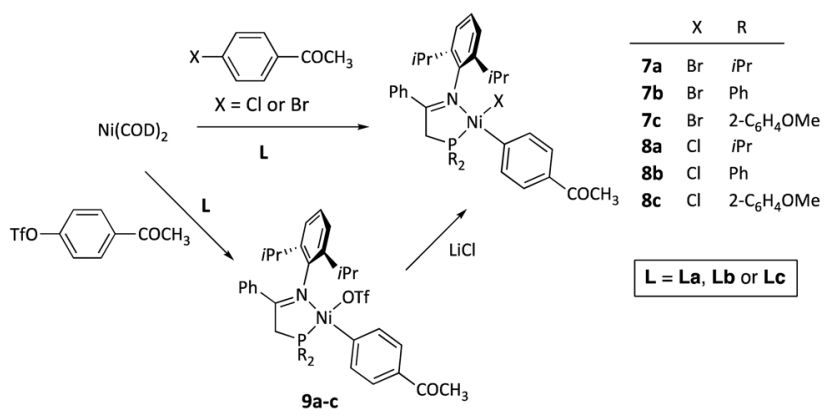

Scheme 5 Oxidative addition of aryl halides and triflate to $\mathrm{Ni}(0) / \mathrm{L}$ combinations.

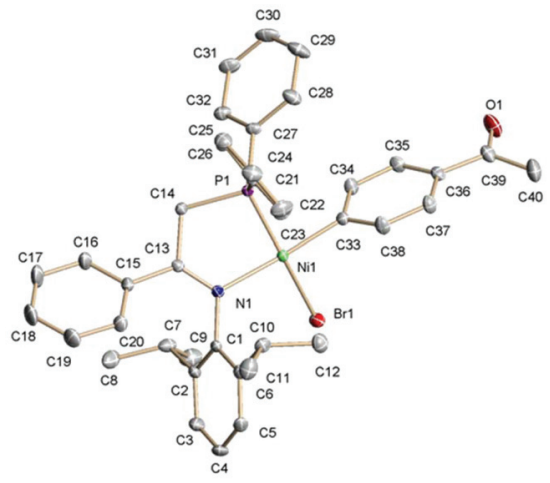

Fig. 4 The crystal structure of $7 \mathrm{~b}$ with $50 \%$ probability thermal ellipsoids. The selected bond distances $(\AA)$ and angles $\left(^{\circ}\right)$ : $\mathrm{Ni}(1)-\mathrm{C}(33)$, 1.8855(19); $\mathrm{Ni}(1)-\mathrm{P}(1), 2.1058(6) ; \mathrm{Ni}(1)-\mathrm{N}(1), 2.0255(16) ; \mathrm{Ni}(1)-\mathrm{Br}(1)$, 2.3239(3); $C(13)-N(1), 1.289(3) ; C(13)-C(14), 1.516(3) ; C(33)-N i(1)-B r(1)$, 89.32(6); and $\mathrm{P}(1)-\mathrm{Ni}(1)-\mathrm{N}(1), 85.34(5)$; torsion: $\mathrm{N}(1)-\mathrm{C}(13)-\mathrm{C}(14)-\mathrm{P}(1)$, 24.5(2); dihedral between DiPP ring and plane $\mathrm{N}(1) \mathrm{C}(12) \mathrm{Ni}(1), 75.7$; dihedral between $\mathrm{Ph}$ ring and plane $\mathrm{C}(13) \mathrm{N}(1) \mathrm{C}(14), 38.4$; and dihedral between planes $\mathrm{Ni}(1) \mathrm{C}(33) \mathrm{Br}(1)$ and $\mathrm{Ni}(1) \mathrm{N}(1) \mathrm{P}(1), 13.7$.

These conclusions were confirmed by the crystal structure of 7b (Fig. 4).

The oxidative addition reactions of the corresponding aryl triflate to $\mathrm{Ni}(\mathrm{COD})_{2} / \mathbf{L}$ proceed with similar colour changes. However, the triflate complexes $\mathbf{9}$ proved to be sensitive materials and their isolation is problematic. For each ligand, a broad resonance is observed for the main product in the ${ }^{31} \mathrm{P}$ $\left\{{ }^{1} \mathrm{H}\right\}$ spectrum of the mixture but as the reaction advances one or two additional signals gradually gain intensity. We attribute the extra signals to the cationic species arising from the replacement of the triflate anion with solvent (THF), adventitious water, or any other potential donor present in the system. The treatment of such mixtures with lithium chloride causes the quantitative exchange of the labile triflate anion for the halide. The ${ }^{31} \mathrm{P}$ spectrum gets simplified, with all signals being replaced with that of the corresponding chloro-complex $($ i.e. $9 \rightarrow 8$ ). This confirms that the aryl triflate undergoes oxidative addition similar to its bromo and chloro analogues.

Next, we investigated a similar oxidative addition of 4-acetylphenyl derivatives to prepare Pd aryl complexes. Initial experiments using $\operatorname{Pd}(\mathrm{DBA})_{2}$ and ligands La-Lc showed that the desired products were formed, but purifying them from the DBA released in the reaction proved a tedious and unpractical task. We then turned to complexes $\mathbf{4 a - c}$ as seemingly ideal starting materials. NMR tests using pure samples of complexes 4 with 4-bromoacetophenone showed that these reactions proceeded smoothly in THF at $60{ }^{\circ} \mathrm{C}$, but they led to mixtures of two P-containing products (Scheme 6 ). No other $\mathrm{P}$ resonances were generated in the process. The integration of the ${ }^{31} \mathrm{P}$ resonances indicates that the combined yields were close to quantitative. Virtually the same results were obtained when the starting materials $\mathbf{4 a - c}$ were generated in situ from $\mathbf{2}$ and La, Lb or Lc, and, therefore this method was systematically applied in further experiments, as described in the experimental section. Evaporation and washing with hexane 

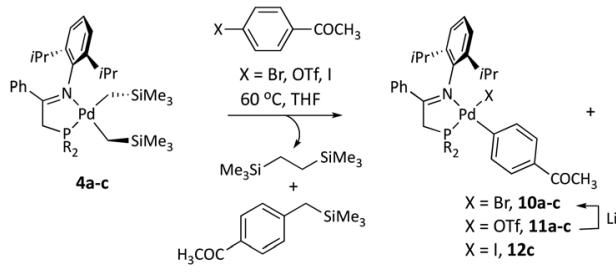

$\left.\begin{array}{ll}X=B r, 10 a-c \\ X=O T f, 11 a-c\end{array}\right]$ LiBr $\left.\begin{array}{l}X=B r, 13 a-c \\ X=O T f, 14 a-c\end{array}\right]$ LiBr $X=1,12 c \quad X=1,15 c$ \begin{tabular}{lll}
$X$ & $R$ & Alkyl/Aryl \\
\hline
\end{tabular} $\mathrm{Br} \quad \mathrm{iPr} \quad 13 \mathrm{Pr} / 10 \mathrm{a} \quad 0.8: 1$ $\mathrm{Br} \quad \mathrm{Ph} \quad 13 \mathrm{~b} / \mathbf{1 0 b} \quad 1.0: 1$ $\begin{array}{llll}\mathrm{Br} \quad \mathrm{O}_{6} \mathrm{H}_{4} \mathrm{OMe} & 13 \mathrm{c} / 10 \mathrm{c} & 0.2: 1\end{array}$ OTf $\quad \mathrm{Pr} \quad 14 \mathrm{ar} / 11 \mathrm{a} \quad 0.4: 1$ OTf $\quad \mathrm{Ph} \quad 14 \mathrm{~b} / 11 \mathrm{~b} \quad 0.3: 1$ OTf $\mathrm{oC}_{6} \mathrm{H}_{4} \mathrm{OMe} \quad 14 \mathrm{c} / 11 \mathrm{c} \quad 0.0: 1$ I $o \mathrm{C}_{6} \mathrm{H}_{4} \mathrm{OMe} \quad 15 \mathrm{c} / 12 \mathrm{C} \quad 0.4: 1$

Scheme 6 Oxidative addition reactions using complexes 4 as $\operatorname{Pd}(0)$ sources.

afforded solids containing mixtures of two organometallic products. A careful analysis of the NMR spectra of these mixtures showed that the products are as shown in Scheme 6. The identity of the Pd-aryl products $\mathbf{1 0 a - c}$ was confirmed by the presence of the characteristic acetyl signal in the spectra, and by a comparison of the chemical shifts of their ${ }^{31} \mathrm{P}$ resonances with those of the same compounds generated from $\operatorname{Pd}(\mathrm{DBA})_{2}$. The identity of the mono-trimethylsilyl species $13 \mathbf{a}-\mathbf{c}$ was ascertained from the characteristic high-field signals of the $\mathrm{CH}_{2} \mathrm{SiMe}_{3}$ group, and the splitting of the $\mathrm{CH}_{2}$ resonance by coupling with the ${ }^{31} \mathrm{P}$ nucleus $\left({ }^{2} J_{\mathrm{HP}} \approx 6 \mathrm{~Hz}\right)$. The crude reaction mixtures were analysed by GC-MS, which led to the detection of the homo-coupling product 1,2-bis(trimethylsily)ethane, along with the cross-coupled 4-(trimethylsilyl)methyl-acetophenone. However, neither 4,4'-diacetylbiphenyl nor acetophenone (hydrodehalogenation product) was detected in the mixtures.

As mentioned above, the use of complex 2 as a practical $\operatorname{Pd}(0)$ precursor is becoming a rather common option in homogeneous catalysis, with preference over conventional sources of $\operatorname{Pd}(0)$. The actual outcome of such "catalyst activation" reactions is seldom investigated, but it has been recently shown that in some cases it can be more complex than foreseen, and affords a number of unexpected side products. ${ }^{23}$ Therefore, we deemed it worthwhile to perform some additional experiments in our system in order to gain some insight into the mechanism of this reaction. First, we examined the reactions of complexes 4 with $p$-acetylphenyltriflate and 4-iodoaceto-phenone (the latter only with 4c). 4-Acetylphenyl triflate reacts with $\mathbf{4 a - c}$ under the same conditions tested with the bromide and, as observed for $\mathrm{Ni}$, the ${ }^{31} \mathrm{P}\left\{{ }^{1} \mathrm{H}\right\}$ spectrum of the final reaction mixture contains several broad signals (up to four), presumably due to the partial replacement of the labile triflate anion of the initial products (11 and 14) with potential ligands present in the mixture (solvent, $\mathrm{H}_{2} \mathrm{O}$ traces, $\mathrm{COD}$, etc.). As observed with the Ni triflates, the treatment of the final reaction mixtures with solid LiBr in excess simplified the ${ }^{31} \mathrm{P}\left\{{ }^{1} \mathrm{H}\right\}$ spectra, with the original broad signals being replaced by the signals of products 10 and 13 previously observed in the reactions with $p$-bromoacetophenone. Interestingly, the oxidative addition of the aryl triflate yields a larger fraction of the aryl products than observed in the reactions with aryl bromide (14/11 ratios shown in Scheme 6 have been determined after anion exchange with $\mathrm{LiBr}$ ), but the alkyl/aryl product ratio exhibits the same general trend for $\mathrm{X}=\mathrm{Br}$ and OTf, decreasing in the order $\mathbf{L a} \approx \mathbf{L b}<\mathbf{L c}$. The oxidative addition of aryl triflate becomes essentially selective for Lc, as after treatment with $\mathrm{LiBr}$, the ${ }^{31} \mathrm{P}\left\{{ }^{1} \mathrm{H}\right\}$ spectrum showed a strongly prevalent resonance for 10c that was subsequently isolated as an analytically pure product and fully characterized. Significantly, GC-MS analysis of the corresponding reaction mixture showed the presence of 1,2-bistrimethylsilylethane, but the cross-coupled organic product was not detected. In contrast, the reaction of 4c with $p$-iodoacetophenone afforded even higher content of the alkyl product than 4-bromoacetophenone. This observation implies that the alkyl ratio increases with the halide or pseudohalide group in the order $\mathrm{I}>\mathrm{Br}>$ OTf.

We proposed the mechanism shown in Scheme 7 to explain our experimental observations. The process begins with the irreversible reductive elimination of 1,2-bistrimethylsilylethane from complexes 4 to generate a $\operatorname{Pd}(0)$ species. Note that the $[(\mathrm{P} \sim \mathrm{N}) \mathrm{Pd}]$ notation does not mean any explicit guess on the actual structure of such a species. The essentially quantitative spectroscopic yields show that the $\operatorname{Pd}(0)$ intermediate is efficiently trapped by the aryl halide. The fact that these intermediates were not detected in the ${ }^{31} \mathrm{P}\left\{{ }^{1} \mathrm{H}\right\}$ monitoring indicates that reductive elimination is slower than any subsequent step or, in other words, the rate determining step. The formation of monalkyl complexes $(\mathbf{1 3}, 14$ and 15) could arise by two different pathways. One of them, represented in the middle line of Scheme 7, is Pd-Pd alkyl-halide exchange (or transmetallation) between the oxidative addition products (10-12) and starting dialkyl 4 to yield an unstable alkyl-aryl

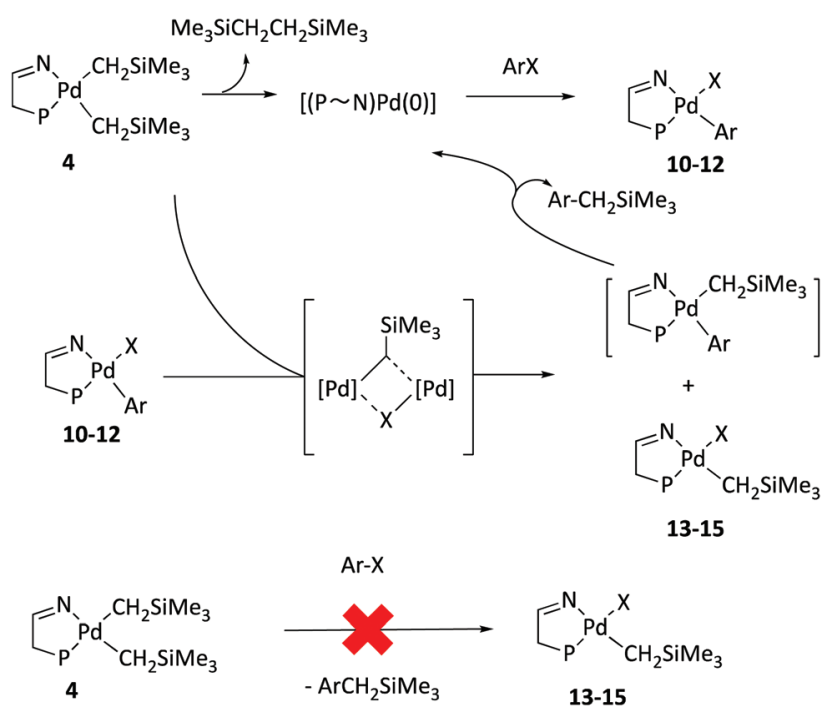

Scheme 7 The possible mechanisms leading to the competitive formation of aryl and alkyl products. Top, generation of a $\mathrm{Pd}(0)$ precursor, followed by oxidative addition. Center, bimolecular alkyl/halide exchange. Bottom, direct reaction of the dialkyl 4 with the electrophile (not operative). 
intermediate. This rapidly undergoes reductive elimination, affording the cross-coupling organic product and regenerating the $\operatorname{Pd}(0)$ species that is recycled through oxidative addition. A similar Pd-Pd aryl-halide transmetallation step was identified by A. Yamamoto in the reaction of palladium diaryls with MeI or aryl halides, ${ }^{24}$ and $\operatorname{Pd}($ II)-Pd(II) aryl exchanges have been subsequently proposed by other authors to occur in Pd-catalyzed reactions. ${ }^{25}$ The bimolecular alkyl-halide exchange is probably driven by the special activation of the $\mathrm{Pd}-\mathrm{C}$ bond placed in trans to the $\mathrm{P}$ donor atom in 4 . This path is consistent with the observed influence of $\mathrm{X}$ (halide or triflate) on the alkyl/aryl ratio, as the better the ability of $\mathrm{X}$ to bridge metal centres, the more efficient the exchange (hence the $\mathrm{I}>\mathrm{Br}>$ OTf trend). The lower alkyl/aryl ratios observed with Lc can be attributed to the lower rate of bimolecular exchange, hampered by the steric hindrance of this bulky ligand. In agreement with the Pd-Pd transmetallation proposal, we confirmed that reacting 1 equiv. of complex $4 \mathbf{b}$ with a $3: 1$ 10b/13b mixture at $60{ }^{\circ} \mathrm{C}$, in the absence of additional $\mathrm{ArBr}$, caused a $30 \%$ enhancement of the signal $\mathbf{1 3 b}$ at the expense of $\mathbf{1 0 b}$, as expected if alkyl-halide exchange occurs between $\mathbf{1 0 b}$ and $\mathbf{4 b}$ concurrently with reductive elimination processes.

An alternative route to the alkyl complexes 13-15, shown in the lower part of Scheme 7, would entail a competitive reaction of the starting dialkyl $\mathbf{4}$ with the aryl halide to afford the corresponding monoalkyl (13-15) and the cross-coupled organic product in a single step. To gather some additional mechanistic information on this regard, we investigated the overall rate of disappearance of $\mathbf{4} \mathbf{b}$ in the presence of 0,2 and 4 equiv. of 4 -bromoacetophenone. At $40^{\circ} \mathrm{C}$ (the lower temperature was selected in order to facilitate data collection) $\mathbf{4 b}$ decays with estimated half-lives of 61, 19 and 17 min, respectively. $\S$ The blank reaction (no electrophile added) leads to a very dark solution probably containing colloidal $\operatorname{Pd}(0)$, and a number of low intensity resonances in the ${ }^{31} \mathrm{P}\left\{{ }^{1} \mathrm{H}\right\}$ spectrum. Thus, albeit the decomposition of $\mathbf{4 b}$ alone is somewhat slower, the half-life of $\mathbf{4} \mathbf{b}$ does not change appreciably when the concentration of the electrophile is increased twofold ( 2 to 4 equiv.), nor does the product ratio $(\mathbf{1 3 b} / \mathbf{1 0 b}=2.1: 1$ in the latter two experiments). This is incompatible with the direct reaction of $\mathbf{4 b}$ with bromoacetophenone, as in this case the reaction rate should exhibit a direct dependency on the concentration of the aryl bromide. The bimolecular exchange mechanism also accounts for the slower decomposition rate in the blank reaction, since the overall rate of decay of $\mathbf{4 b}$ is the sum of the reductive elimination and the bimolecular exchange reactions, and the latter does not occur in the absence of the electrophile. To confirm that the electron-poor aryl halide is not accelerating reductive elimination on $\mathbf{4 b}$, via transient coordination of the electrophile, we carried out two

$\S$ The half-lives were estimated from approximate first-order kinetic plots, but this reaction is not expected to obey a simple kinetic law. At this stage, a comparison of overall reaction rates suffices to draw some valuable conclusions regarding the influence of the aryl bromide concentration on the reaction rate and product distribution. further control experiments. In these experiments complex $\mathbf{4 b}$ was allowed to decompose at $40{ }^{\circ} \mathrm{C}$ in the presence of 2 and 4 equivalents of methyl acrylate, an electron-poor olefin that could also act as a reductive elimination promotor. ${ }^{26}$ The halflives of $\mathbf{4 b}$ in these experiments were 60 and $49 \mathrm{~min}$, fairly similar to those measured in the blank experiment, which confirmed that the role of reductive elimination enhancement by the electrophile is marginal, at best.

In closing this section, it is worth highlighting the marked effect of temperature on the $\mathbf{1 3 b / 1 0 b}$ ratio: the selectivity of the oxidative addition product actually decreased by a factor of 2 when the reaction temperature was lowered from 60 to $40{ }^{\circ} \mathrm{C}$, giving a cautionary warning on the practical applications of bis(alkyl)Pd(II) complexes as a source of Pd(0). According to our mechanistic proposal, the product ratio is dictated by the relative rates of the alkyl/halide exchange step (a bimolecular reaction) and reductive elimination (a unimolecular process). Bimolecular processes have strongly negative activation entropies, and therefore their rates scale more slowly with temperature compared with those of the unimolecular reactions. Thus, the formation of the alkyl side product is expected to decrease or even to be suppressed as the temperature is increased. A similar argument leads to the conclusion that the alkyl/aryl product ratio will increase with the overall Pd concentration (i.e., the initial concentration of the starting dialkyl 4), as the rate of the comproportionation step has a quadratic dependency on concentration, vs. simple dependency for the reductive elimination rate. Low temperatures and high concentration of the starting dialkyl are conditions favorable for organometallic synthesis, whilst in catalysis very diluted metal complexes and relatively high temperatures are commonly used. The conclusion is that using complex 2 as a $\operatorname{Pd}(0)$ equivalent may be appropriate for catalytic applications, but can be inconvenient for synthetic purposes, due to the formation of the mono(trimethylsilyl)methyl product as an awkward byproduct.

\section{Reversible acid-base reactions of nickel iminophosphine/ enaminate complexes}

In addition to $\mathrm{NaH}$, other strong bases such as $t \mathrm{BuOK}, \mathrm{Cs}_{2} \mathrm{CO}_{3}$ and DBU deprotonate $\mathbf{6 b}$ in THF (Scheme 8). When these reactions were monitored using ${ }^{31} \mathrm{P}\left\{{ }^{1} \mathrm{H}\right\}$ spectra, the resonance of the starting material at $42.5 \mathrm{ppm}$ was replaced in all cases with that of $\mathbf{3 b}$ at $33.2 \mathrm{ppm}$ (both in THF). In contrast, triethylamine, diisopropyl(ethyl)amine (Hunig's base) or proton sponge fail to induce any change in the spectrum, either at room temperature or after heating to $60^{\circ} \mathrm{C}$. The addition of one equivalent of HOTf to solution of $\mathbf{3 b}$ generated with either $\mathrm{NaH}$ or $t \mathrm{BuOK}$ caused the disappearance of its ${ }^{31} \mathrm{P}$ resonance and restored that of $\mathbf{6 b}$, demonstrating the full reversibility of these acid-base processes.

As an insoluble, hence heterogeneous base, $\mathrm{NaH}$ is efficient but slow. In contrast, soluble bases ( $t \mathrm{BuOK}$ and DBU) or partially soluble ones $\left(\mathrm{Cs}_{2} \mathrm{CO}_{3}\right)$ deprotonate $\mathbf{6 b}$ rapidly. Upon treatment with such bases, $6 \mathbf{b}$ is consumed within the time required to carry the sample into the NMR probe. Whereas 


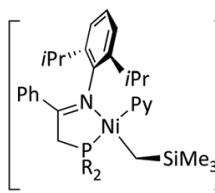

$6 b$

Base: $\mathrm{NEt}_{3} \approx \mathrm{N}(\mathrm{iPr})_{2} \mathrm{Et} \approx$ proton sponge $<\mathrm{DBU}<\mathrm{Cs}_{2} \mathrm{CO}_{3}<\mathrm{KtBuO}<\mathrm{NaH}$ $\mathrm{p} K_{\mathrm{aH}}$

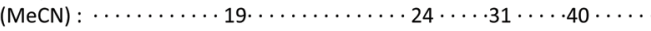

(THF): $\cdots \cdots \cdots 11-12 \ldots \ldots \cdots \cdots \cdots \cdots \cdots \cdots \cdots \cdots \cdots$

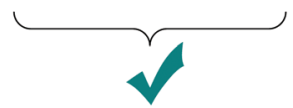

Scheme 8 Reversible deprotonation of cationic nickel iminophosphine complexes to neutral phosphinoenaminate with different base strengths.

reactions with $\mathrm{NaH}, t \mathrm{BuOK}$, and $\mathrm{Cs}_{2} \mathrm{CO}_{3}$ are essentially quantitative, the intensity of the signal of $3 \mathbf{b}$ in the experiment with 1 equiv. of DBU was $c a .25 \%$ of the expected value, though it was the only detected resonance in the final spectrum. An excess of this base (5 equiv.) causes irreversible decomposition, the final spectrum showing a number of low intensity

${ }^{31} \mathrm{P}$ resonances different from those of $\mathbf{3 b}$ or $\mathbf{6 b}$, those of the free ligand $\mathbf{L b}$ amongst them.

A basicity scale is displayed at the bottom of Scheme 8 ( $\mathrm{p} K_{\mathrm{aH}}$ is the $\mathrm{p} K_{\mathrm{a}}$ of the acid conjugates in organic, non-protic solvents ${ }^{27}$ ). Consistent with our qualitative observations, bases placed below DBU in the scale fail to perform the deprotonation of $\mathbf{6 b}$, at least to a noticeable extent. Thus, it can be assumed that the basicity of $\mathbf{3 b}$ is comparable with that of DBU. Very likely, the decomposition problems observed with this base relate to incomplete deprotonation of the iminophosphine ligand, allowing some other undisclosed processes to compete and, eventually, causing decomposition of the material (note that DBU is a non-innocent base, as it is also a potent coordinating ligand towards $\mathrm{Ni}^{28}$ ). Interestingly, whilst the transformations associated with the stronger bases $\mathrm{NaH}$ or $\mathrm{K}^{t} \mathrm{BuO}$ generate a narrow signal of $\mathbf{3 b}$, the same signal appears broad in the spectra generated with $\mathrm{Cs}_{2} \mathrm{CO}_{3}$ or DBU, suggesting that in these cases reversible proton exchange equilibria are established.

In a further test, we explored the capacity of iminophosphine ligands to support reversible deprotonation in a different coordination environment, carrying out the reaction

IThe approximate basicity scales shown in Scheme 8 are based on the $\mathrm{p} K_{\mathrm{a}}$ values measured for the corresponding conjugate acids in different nonaqueous acids. The largest series of $\mathrm{p} K_{\mathrm{a}}$ values are available in MeCN (DBU-H ${ }^{+}, 24.3$; $\mathrm{H}$-proton sponge ${ }^{+}, 18.6$; and ${\mathrm{H}-\mathrm{NEt}_{3}}^{+}, 18.6$ ) (see ref. 28a). Other values can be estimated from other solvents using empirical correlations for $\mathrm{X}-\mathrm{OH}$ acids (ref. 28b): $\mathrm{p} K_{\mathrm{a}}$ in $\mathrm{MeCN}=\mathrm{p} K_{\mathrm{a}}$ in DMSO +10.5 (used for $t \mathrm{BuOH}, \mathrm{p} K_{\mathrm{a}}=29.4$ in DMSO, ref. $28 c)$ and $\mathrm{p} K_{\mathrm{a}}$ in $\mathrm{MeCN}=1.6 \cdot \mathrm{p} K_{\mathrm{a}}$ in $\mathrm{H}_{2} \mathrm{O}+14.9$ for $\mathrm{HCO}_{3}{ }^{-}\left(\mathrm{p} K_{\mathrm{a}}=10.3\right.$ in $\left.\mathrm{H}_{2} \mathrm{O}\right)$ as an estimation for $\mathrm{Cs}_{2} \mathrm{CO}_{3}$. Similar correlations are not available for THF but the $\mathrm{p} K_{\mathrm{a}}$ values in this solvent are also given in ref. $28 a$ for $\mathrm{HNEt}_{3}{ }^{+}$(12.5), H-proton sponge ${ }^{+}$(11.1) and DBU (16.6).

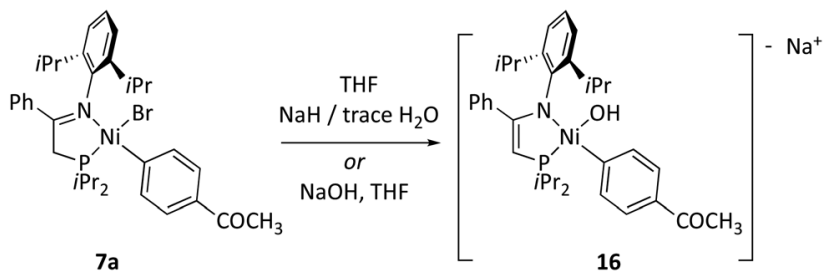

Scheme 9 Deprotonation of complex 7a.

of a nickel aryl complex 7a with $\mathrm{NaH}$. Note that 7a has at least two potentially reactive points for a strong base, the iminophosphine ligand, and the acetyl group. In addition, the deprotonation of a neutral complex should lead to an anionic species. The latter could eliminate insoluble sodium bromide leaving an unstable, coordinatively unsaturated complex. Thus, we were pleased to observe that $7 \mathbf{a}$ reacts cleanly in THF solution with a large excess of solid $\mathrm{NaH}$ (>10 eq.), affording a single ${ }^{31} \mathrm{P}$-containing product $\mathbf{1 6}$. This was isolated as a highly sensitive brick-red solid, nearly insoluble in $\mathrm{C}_{6} \mathrm{D}_{6}$, that decomposed in $\mathrm{CD}_{2} \mathrm{Cl}_{2}$. The ${ }^{1} \mathrm{H}$ NMR spectrum, recorded in THF- $d_{8}$, showed a signal for the enaminate $\mathrm{CH}$ at $3.04 \mathrm{ppm}$ with a small coupling to ${ }^{31} \mathrm{P}(1.5 \mathrm{~Hz})$, and the usual $3 \mathrm{H}$-intensity of the $p$-acetyl resonance at $2.33 \mathrm{ppm}$ that confirmed that only the iminophosphine ligand had been deprotonated. These spectroscopic properties, in addition to its insolubility in hydrocarbon solvents, suggested that 16 might be an anionic complex of the type $\left[\mathrm{Ni}\left(\mathbf{L}^{\prime} \mathbf{a}\right)(\mathrm{X})\left(p-\mathrm{C}_{6} \mathrm{H}_{4} \mathrm{COCH}_{3}\right)\right]^{-} \mathrm{Na}^{+}$, with $\mathbf{L}^{\prime} \mathbf{a}$ representing the conjugate base of ligand La, as shown in Scheme 9. Surprisingly, the ${ }^{1} \mathrm{H}$ NMR spectrum also shows a high-field resonance $(-2.78 \mathrm{ppm})$ integrating for $1 \mathrm{H}$, which suggests that $\mathrm{X}$ could be a hydroxide ligand. Accordingly, the IR spectrum of 16 shows a weak, but sharp band at $3584 \mathrm{~cm}^{-1}$, overlapping an intense but broader one centered at $3422 \mathrm{~cm}^{-1}$, which is consistent with a partially associated hydroxide ligand. The hydroxide could come from $\mathrm{Br}$ exchange with a small amount of $\mathrm{NaOH}$ in sodium hydride, used in a large excess (10-fold), or may be generated by the interaction of $\mathrm{NaH}$ with moisture traces. As a matter of fact, we confirmed that $7 \mathbf{a}$ is also cleanly deprotonated by a suspension of $\mathrm{NaOH}$ in anhydrous THF, directly yielding the same product 16 in essentially quantitative yield. Complex 16 was crystallized by layering THF solution with diethyl ether, and its crystal structure was determined (Fig. 5).

The structure of $\mathbf{1 6}$ confirmed the presence of the anionic enaminato(aryl)nickel moiety, with a hydroxo ligand occupying the fourth coordination position. In the solid state, the sodium cation coordinates to the hydroxo ligand, through a strong (short) Na-O bond $(2.160(2) \AA)$, and completes its coordination sphere with two ether molecules (one THF and one $\mathrm{Et}_{2} \mathrm{O}$ ), and a dative interaction with the acetyl oxygen atom belonging to a second coordination unit. This gives rise to a dimeric molecular entity in the solid state. This arrangement presents a contact $(3.080(3) \AA)$ between the sodium atom and $\mathrm{C} 28$, one of the carbon atoms of the aromatic ring bound to the Ni center. The coordination environment of $\mathrm{Na}$ in this 


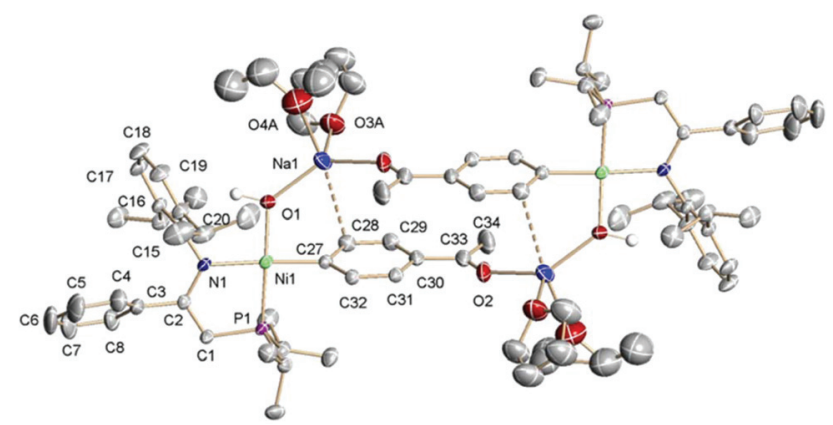

Fig. 5 The crystal structure of complex $16 \cdot\left(\mathrm{THF} \mathrm{Et}_{2} \mathrm{O}\right)$ with $50 \%$ probability thermal ellipsoids. The selected bond distances (Å): Ni1-O1, 1.8916(18); Ni1-C27, 1.896(3); Ni1-N1, 1.981(2); Ni1-P1, 2.1438(12); N1$\mathrm{C} 2,1.363(3) ; \mathrm{C}(33)-\mathrm{O}(2), 1.214(4) ; \mathrm{C}(33)-\mathrm{C}(30), 1.483(4) ; \mathrm{C}(33)-\mathrm{C}(34)$, 1.510(5); O1-Na1, 2.160(2); O2-Na1', 2.271(3); O3A-Na1, 2.335(4); O4A$\mathrm{Na1}, 2.384(4)$; and $\mathrm{Na1}-\mathrm{C}(28), 3.080(3)$. The selected angles $\left({ }^{\circ}\right)$ : O1-N1$\mathrm{C} 27,87.41(19)$ and N1-Ni1-P1, 85.49(6); torsion: N1=C2-C1-P1, 4.0(3); and angle between planes $\mathrm{O} 1-\mathrm{Ni1}-\mathrm{C} 27$ and N1-Ni1-P1, 9.2.

molecule is most likely contingent upon the choice of the solvent and crystallization conditions. In solution, it would be reasonable to assume that $\mathbf{1 6}$ has the ion pair structure shown in Scheme 9, with an external $\mathrm{Na}^{+}$cation fully solvated with THF. The Ni-O distance $(1.889(2) \AA)$ is similar to that found in other square-planar, monomeric Ni(II) hydroxides reported in the literature, either neutral or anionic. ${ }^{29}$

It is remarkable that the deprotonation of $7 \mathbf{a}$ should afford selectively complex $\mathbf{1 6}$, as $\mathrm{NaH}$ is one of the bases commonly used to generate enolates from ketones. The low acidity of the acetyl group of this organometallic complex is probably due to the influence of the electron-rich $\mathrm{Ni}$ fragment connected to the para position in the aryl ring. Since 7a arises from the oxidative addition of a functional aryl halide to a Ni(0) species, the outcome of this experiment is relevant for potential applications of the nickel-iminophosphine system in cross-coupling catalysis.

\section{Conclusions}

In this article we explored the ability of iminophosphine ligands to stabilize a variety of organonickel and organopalladium complexes, supporting reversible deprotonation and oxidative addition reactions. The syntheses of such complexes have been adapted to each of these metals. Thus, ligand exchange reactions from suitable bis(trimethylsilyl)methyl precursor complexes with La-Lc have divergent results for $\mathrm{M}=\mathrm{Ni}$ (1) or Pd (2) probably due to the different sizes of the metal atoms. The exchange is straightforward for the latter affording dialkylpalladium complexes $\mathbf{4 a - c}$. In contrast, dialkyl precursor 1 reacts with iminophosphine Lb affording the phosphinoenaminate complex $\mathbf{3 b}$. We devised a general synthesis of nickel phosphinoenaminates 3 , starting from the new cationic monoalkylnickel precusor 5. Neutral arylnickel complexes were readily obtained via oxidative additions to mixtures
$\mathrm{Ni}(\mathrm{COD})_{2}+\mathbf{L}$. The use of complexes $\mathbf{4 a - c}$ as $\operatorname{Pd}(0)$ sources for the analogous oxidative addition reactions was found unpractical for synthetic purposes, due to the formation of undesired side products arising from competitive $\mathrm{Pd}(\mathrm{II})-\mathrm{Pd}(\mathrm{II})$ alkyl/halide exchange. The weak acidic character of the phosphino-imine ligand is a source of interesting reactivity with potential applications in catalysis. We have demonstrated the reversibility of the deprotonation of this ligand for $\mathrm{Ni}$, a potential route for cooperative metal-ligand behavior. Tests with bases of different strengths indicate that the iminophosphine/phosphinoenaminate pair in the coordination sphere of $\mathrm{Ni}$ is an acid/ base pair comparable to $\mathrm{H}-\mathrm{DBU}^{+} / \mathrm{DBU}$ pair. Interestingly, neutral halo(aryl) complexes arising from the oxidative addition of 4-bromoacetophenone are selectively deprotonated at the iminophosphine ligand, even with strong bases, affording an unusual type of anionic arylnickel complex. These results open interesting prospects in the application of nickel complexes as catalysts for coupling reactions such as the Heck or Suzuki reactions, with iminophosphine ligands acting as auxiliaries in proton transfer steps, or base-promoted activation of the electrophile.

\section{Experimental section}

\section{General considerations}

All manipulations were carried out under an inert atmosphere, either using the standard Schlenk technique in a vacuum line operating with purified argon, or a nitrogen-filled glove box equipped with a pump for solvent evaporation, an externally cooled (with liquid $\mathrm{N}_{2}$ ) cavity, a freezer and an analytical balance. The following paragraphs provide a summary of the general procedures, and a full description of the syntheses and complete spectroscopic and analytical data are given in the ESI + for all ligands and complexes.

General procedure for the synthesis of iminophosphine ligands (La, Lb, and $\mathbf{L c}$ ). To a solution of imine $\mathrm{Ph}(\mathrm{Me}) \mathrm{C}=\mathrm{N}$ (DiPP) $(0.560 \mathrm{~g}, 2 \mathrm{mmol})$ in THF $(10 \mathrm{~mL})$, stirred at $-80{ }^{\circ} \mathrm{C}$, was added $1.6 \mathrm{~mL}$ of a $1.7 \mathrm{M}$ solution of ${ }^{t} \mathrm{BuLi}$ in pentane (2.72 mmol). The stirring was continued for 30 minutes, and then the cooling bath was removed allowing the mixture to warm to room temperature. Then, the volume corresponding to 1 equivalent of the corresponding chlorophosphine ( $2 \mathrm{mmol}$ ) was added, and the stirring was continued, monitoring the reaction by ${ }^{31} \mathrm{P}$ NMR spectroscopy. Usually, the reactions were complete within ca. $30 \mathrm{~min}$. The solvent was removed under vacuum and the residue was then extracted with $n$-hexane $(40 \mathrm{~mL})$ and the extract was filtered through Celite. Evaporation under reduced pressure leaves a paleyellow oil that can be stored at $5{ }^{\circ} \mathrm{C}$ under an $\mathrm{Ar}$ atmosphere.

\section{Ligand exchange reactions}

Reaction of iminophosphine ligands La-Lc with nickel precursor 1

Isolation of $\mathbf{3 b}$. To a solution of complex 1 (0.115 g, $0.3 \mathrm{mmol}$ ) in $10 \mathrm{~mL}$ of $\mathrm{THF}$, stirred at $-80{ }^{\circ} \mathrm{C}$, was added an 
equimolar amount of the corresponding ligand (La, Lb or $\mathbf{L c}$ ), dissolved in $1.5 \mathrm{~mL}$ of THF. The mixture was stirred for $5 \mathrm{~min}$, and then allowed to stir at room temperature. The ${ }^{31} \mathrm{P}\left\{{ }^{1} \mathrm{H}\right\}$ spectra of the reaction mixtures were recorded periodically. The initial spectra, recorded after $1 \mathrm{~h}$, showed several signals, including some unreacted free ligands. After $20 \mathrm{~h}$, the spectrum of the mixture generated from $\mathbf{L b}$ showed a single signal at 32.3 ppm (together with a small amount of unreacted $\mathbf{L b}$ ), but those generated from La and Lc still showed a number of peaks that revealed the existence of a number of different products. After this time, the mixtures were evaporated, the residues taken up in $\mathrm{Et}_{2} \mathrm{O}(15 \mathrm{~mL})$ and the solutions filtered through Celite. These were concentrated and some hexane was added until becoming slightly turbid. Cooling in the freezer $\left(-25^{\circ} \mathrm{C}\right.$ ) led to the crystallization of $\mathbf{3 b}$ (from $\mathbf{L b}$ ), but no solid products crystallized from the mixtures generated from La or Lc. The red-orange crystals of $\mathbf{3} \mathbf{b}$ were collected by filtration, and a small sample of crystals was reserved for X-ray analysis. The remaining product was washed with some hexane and dried in vacuo. Yield, $0.084 \mathrm{~g}, 0.12 \mathrm{mmol}, 40 \%$. Complete spectroscopic data for $\mathbf{3 b}$ can be found in the ESI. $\$$

General procedure for the preparation of dialkyl palladium(II) complexes $4 a-c$. A solution of $c a$. $0.1 \mathrm{mmol}$ complex bis[(trimethylsilyl)methyl] (1,5-cyclooctadiene) palladium(II) (2) in $3 \mathrm{~mL}$ of $\mathrm{THF}$, cooled at $-80^{\circ} \mathrm{C}$, was treated with a solution containing an equimolar amount of the corresponding ligand (La, Lb or Lc) in $1 \mathrm{~mL}$ of THF. The mixtures were stirred at this temperature for 5 minutes, then the cold bath was removed and the mixtures stirred at room temperature for $1 \mathrm{~h}$. Upon completion of the reaction, the products were separated by filtration, washed with cold hexane, and dried under vacuum. These were crystallized either from $n$-pentane or from a $\mathrm{CH}_{2} \mathrm{Cl}_{2} / n$-hexane mixture, and stored in glass vials in the glove-box freezer at $-25^{\circ} \mathrm{C}$.

General procedure for the preparation of cationic monoalkyl nickel(II) complexes $\mathbf{6 a - c}$. First, complex $\mathbf{5}$ was generated in situ: in the glove box, a vial containing a solution of $\mathrm{Ni}\left(\mathrm{CH}_{2} \mathrm{SiMe}_{3}\right)_{2} \mathrm{Py}_{2}$ in THF (e.g. $0.25 \mathrm{mmol}$ in $2 \mathrm{~mL}$ ) was placed in a well cooled to $\mathrm{N}_{2}(l)$ temperature, and treated with a solution containing the exact equimolar amount of $\left[\mathrm{Py}_{2} \mathrm{H}\right]^{+}[\mathrm{TfO}]^{-}$in the same amount of THF. The mixture was shaken and allowed to stir for $1 \mathrm{~h}$ at $25{ }^{\circ} \mathrm{C}$. Once the reaction was completed, to the resulting solution of $\mathbf{5}$ was added a solution containing the equivalent amount of the corresponding ligand $\mathbf{L a}, \mathbf{L b}$ or $\mathbf{L c}$, and the stirring was continued for one more hour. The solvent was evaporated under vacuum and the residue washed/solidified with $5 \mathrm{~mL}$ of cold hexane (precooled at $\mathrm{N}_{2}(l)$ temperature). The products were recrystallized by slow diffusion of hexane into a solution of the complex in $\mathrm{CH}_{2} \mathrm{Cl}_{2}$ at $-25{ }^{\circ} \mathrm{C}$.

\section{Syntheses of neutral alkylnickel complexes $\left[\mathrm{Ni}\left(\mathrm{CH}_{2} \mathrm{SiMe}_{3}\right)\left(\mathrm{L}^{\prime}\right)\right.$} (Py)] ( L' = deprotonated L), 3a-c

General procedure. The syntheses of these complexes were carried out using a one-pot procedure starting from precursor 1, $\left[\mathrm{HPy}_{2}\right]^{+} \mathrm{OTf}^{-}$, and the corresponding ligand $\mathbf{L a}, \mathbf{L b}$ or Lc. In the glove box, a solution containing the appropriate cationic precursor $(\mathbf{6 a}, \mathbf{6 b}$ or $\mathbf{6 c})$ in $2 \mathrm{~mL}$ of THF, generated as described above, starting from equimolar amounts ( $c a .0 .250 \mathrm{mmol}$ ) of $\mathbf{1}$, $\left[\mathrm{HPy}_{2}\right]^{+} \mathrm{OTf}^{-}$and the corresponding ligand, was transferred to a scintillation vial charged with a 10 -fold excess of $\mathrm{NaH}$ and a small magnetic bar. The mixture was stirred for $1 \mathrm{~h}$ at room temperature, after which time the solution was separated from the solids using a syringe capped with a PTFE $0.45 \mu \mathrm{M}$ HPLC filter. Next, the clear solution was dried under vacuum and the residue was extracted with a suitable low-polarity solvent (see specific descriptions) to remove the NaOTf that might remain in the sample. The solution was filtered through the HPLC filter and evaporated. If necessary, the residue can be recrystallized by taking it up in a minimum amount of dichloromethane, layering the solution with hexane and allowing the liquids to slowly diffuse one into another at the box freezer temperature $\left(-25^{\circ} \mathrm{C}\right)$. The solids were separated, washed with a small amount of hexane and dried under vacuum.

\section{Oxidative addition of $4-\mathrm{X}-\mathrm{C}_{6} \mathrm{H}_{4} \mathrm{COMe}$ to $\mathrm{Ni}(0) / \mathrm{L}(\mathrm{L}=\mathrm{La}$, Lb or Lc; and $\mathrm{X}=\mathrm{Br}$ or $\mathrm{Cl}$ )}

Synthesis of the aryl derivatives $7 \mathrm{a}-\mathrm{c}(\mathrm{X}=\mathrm{Br})$ and $8 \mathrm{a}-\mathrm{c}$ $(\mathbf{X}=\mathbf{C l})$

General procedure. A $100 \mathrm{~mL}$ round-bottom Schlenk flask loaded with $\mathrm{Ni}(\mathrm{COD})_{2}(c a .1 \mathrm{mmol})$, THF (ca. $\left.10 \mathrm{~mL}\right)$ and a stirring bar was cooled to $-80{ }^{\circ} \mathrm{C}$. To the stirred suspension was added a solution containing equimolar amounts of the corresponding ligand (La, Lb or $\mathbf{L c}$ ) and the aryl halide. After $5 \mathrm{~min}$, the cooling bath was removed. As the reaction mixture approached the room temperature, the colour became dark brown. As the stirring was continued at room temperature, the color turned gradually to dark yellow. After $2 \mathrm{~h}$, the mixture was evaporated under reduced pressure. The oily residue was extracted with $\mathrm{CH}_{2} \mathrm{Cl}_{2}$, and the solution was filtered through a Celite plug. The clear solution was evaporated and the oily residue cooled to $-80{ }^{\circ} \mathrm{C}$ and vigorously washed with $2 \times 20$ $\mathrm{mL}$ of diethyl ether. The ether washings were discarded, and the resulting powdery solid was dried under vacuum. The powders were spectroscopically pure, but they were recrystallized by slow diffusion of $\mathrm{Et}_{2} \mathrm{O}$ or hexane into a cold, concentrated $\mathrm{CH}_{2} \mathrm{Cl}_{2}$ solution, in the glove box freezer.

\section{Oxidative addition of 4-TfO- $\mathrm{C}_{6} \mathrm{H}_{4} \mathrm{COMe}$ to $\mathrm{Ni}(0) / \mathrm{L}(\mathrm{L}=\mathrm{La}, \mathrm{Lb}$ or Lc)}

General procedure. In the glove box, a scintillation vial was charged with an amount close to $0.05 \mathrm{mmol} \mathrm{Ni}(\mathrm{COD})_{2}$ and a small stirring bar. The vial was placed in a well cooled to liquid nitrogen temperature, a THF solution containing equimolar amounts of the corresponding ligand ( $\mathbf{L a}, \mathbf{L b}$ or $\mathbf{L c}$ ) and $4-\mathrm{TfOC}_{6} \mathrm{H}_{4} \mathrm{COCH}_{3}$ was added, and the total volume was adjusted to $1 \mathrm{~mL}$ with THF. The vial was placed on a magnetic stirrer and allowed to stir at room temperature. As the mixture warmed, its color changed similarly to the reactions with 4-bromo- or 4-chloroacetophenone, becoming first dark brown, and then changing gradually to a yellow or greenishyellow hue. After $1 \mathrm{~h}$, the mixture was transferred to a gas-tight (PTFE-valve) NMR tube containing a sealed glass capillary with 
the external standard $\left(\mathrm{PPh}_{3}\right.$ and $\mathrm{C}_{6} \mathrm{~F}_{6}$ in $\left.\mathrm{C}_{6} \mathrm{D}_{6}\right)$, in order to record its ${ }^{31} \mathrm{P}\left\{{ }^{1} \mathrm{H}\right\}$ and ${ }^{19} \mathrm{~F}$ NMR spectra. These spectra showed a number of broad signals different from those of the starting materials (ligand $\left({ }^{31} \mathrm{P}\right)$ and the organic triflate $\left({ }^{19} \mathrm{~F}\right.$, $\delta-76.1 \mathrm{ppm}$ in THF). In order to confirm that these samples contain a mixture of the oxidative addition complex $(\mathbf{9 a}, \mathbf{9 b}$ or 9c), and the related ionic species arising from the displacement of the triflate anion, these mixtures were converted into the previously known chloro complexes $(\mathbf{8 a}, \mathbf{8 b}$ or $\mathbf{8 c})$, as follows: the NMR tube was brought back to the glove box, where it was open and a 10 -fold excess of solid LiCl was added. The mixture was gently shaken and placed in the ultrasound bath to activate the solid LiCl. After allowing the solids to settle, the ${ }^{31} \mathrm{P}\left\{{ }^{1} \mathrm{H}\right\}$ spectra were recorded, which showed a single, sharp signal for the corresponding chloro derivative $\left({ }^{31} \mathrm{P}\left\{{ }^{1} \mathrm{H}\right\}\right.$ in THF, reference vs. external $\mathrm{PPh}_{3}: \delta 46.4(8 \mathrm{a}), 34.1$ (8b) and $25.0(\mathbf{8 c}))$. The integration of these signals vs. the external reference showed that the total ${ }^{31} \mathrm{P}$ intensity was held constant after the triflate/chloride exchange.

In order to confirm that the final products were chloro derivatives, the oxidative addition reaction of $\mathrm{Ni}(\mathrm{COD})_{2}$ with Lb and $4-\mathrm{TfOC}_{6} \mathrm{H}_{4} \mathrm{COCH}_{3}$ was carried out on a preparative scale $(1 \mathrm{mmol})$, following the same procedure described above for the oxidative addition of 4-haloacetophenones, except that a ten-fold excess of $\mathrm{LiCl}$ was added once the oxidative addition reaction was complete. The usual workup yielded the expected complex $\mathbf{8 b}$, which was identical to the sample obtained from 4-chloroacetophenone. The ${ }^{31} \mathrm{P}\left\{{ }^{1} \mathrm{H}\right\}$ spectrum of the intermediate triflate complex $9 \mathbf{b}$ (THF solution, external $\mathrm{PPh}_{3} / \mathrm{C}_{6} \mathrm{D}_{6}$ reference) showed two broad signals at $\delta 37.3$ (major) and 40.4 (minor), and the ${ }^{19} \mathrm{~F}$ spectrum showed a prominent signal at $\delta 80.3$, probably due to the coordinated or ion-paired triflate anion. All attempts to isolate the intermediate triflate complex $9 \mathbf{b}$ were unsuccessful.

\section{Studies on the oxidative addition of $p-\mathrm{XC}_{6} \mathrm{H}_{4} \mathrm{COCH}_{3}$ to $\operatorname{Pd}(0)$ using complex 2 as a precursor}

Qualitative experiments. A solution containing a precisely weighed amount of the precursor $2(c a .0 .2 \mathrm{mmol})$ was dissolved in $c a .15 \mathrm{~mL}$ of THF, and transferred to a glass ampoule with PTFE valve, and the content was cooled to $-80^{\circ} \mathrm{C}$. To this solution was added 1 equiv. of the corresponding iminophosphine ligand (La, Lb or Lc) dissolved in THF ( $c a .1 \mathrm{~mL}$ ). The solution was stirred for $1 \mathrm{~h}$ at room temperature to ensure the complete displacement of COD and formation of the corresponding complex, $\mathbf{4 a}, \mathbf{4} \mathbf{b}$ or $\mathbf{4 c}$, respectively. To this solution was added 1 equiv. of the corresponding aryl halide or triflate dissolved in ca. 1 equiv. of THF. The ampoule was heated in an oil bath at the prescribed temperature, and the contents were periodically analyzed by recording their ${ }^{31} \mathrm{P}\left\{{ }^{1} \mathrm{H}\right\}$ NMR spectra in THF with an external $\mathrm{PPh}_{3} / \mathrm{C}_{6} \mathrm{D}_{6}$ standard sealed in a glass capillary. When the reaction was completed, the contents were worked-up as follows: for the reactions with 4-bromoacetophenone, a small sample was removed and subjected to GC-MS analysis. The remaining sample was dried, washed with cold hexane, and the residue was analyzed by ${ }^{1} \mathrm{H}$ and ${ }^{31} \mathrm{P}\left\{{ }^{1} \mathrm{H}\right\}$ spec- troscopy. The mixtures produced by reaction with 4-acetylphenyl triflate were also analyzed by GC-MS, but the main fraction was treated with a two-fold excess of $\mathrm{LiBr}$ and stirred for over $1 \mathrm{~h}$. The ${ }^{31} \mathrm{P}\left\{{ }^{1} \mathrm{H}\right\}$ NMR spectra of these mixtures showed the same signals observed in the reactions with 4-bromoacetophenone. Following this procedure, 10c was isolated as a pure product as specified below, and complete NMR data were collected for this compound. In order to assign the signals corresponding to the aryl oxidative addition products, 10a and 10b, separate NMR tests were carried out in which equimolar amounts of $c a .0 .05 \mathrm{mmol} \operatorname{Pd}(\mathrm{DBA})_{2}$ and the corresponding ligand (La or $\mathbf{L b}$ ) in THF (external $\mathrm{PPh}_{3} / \mathrm{C}_{6} \mathrm{D}_{6}$ glass capillary reference) were heated to $60^{\circ} \mathrm{C}$ until the reaction proved completed (ca. $3 \mathrm{~h}$ ), and the ${ }^{31} \mathrm{P}\left\{{ }^{1} \mathrm{H}\right\}$ spectrum of the resulting oxidative addition product was compared with that of the sample. The selected NMR data for the monoaryl and monoalkyl complexes are listed below.

In a separate experiment, a solution of complex $\mathbf{4 b}$ in THF was generated as indicated above, and then split in two equal parts. To one of them was added the stoichiometric amount of $p$-bromoacetophenone, and heated at $60{ }^{\circ} \mathrm{C}$ until completion. A ${ }^{31} \mathrm{P}\left\{{ }^{1} \mathrm{H}\right\}$ NMR spectrum showed that the corresponding mixture of complexes $\mathbf{1 0 b}$ and $\mathbf{1 3 b}$ had been formed. To this mixture was added the second half of the $\mathbf{4 b}$ solution, and the combination was heated again to $60{ }^{\circ} \mathrm{C}$, until the ${ }^{31} \mathrm{P}$ resonance of $\mathbf{4 b}$ disappeared. The final ${ }^{31} \mathrm{P}$ spectrum showed an enhancement of the signal of $\mathbf{1 3 b}(c a .30 \%)$ and a decrease of that of $10 b$ by a similar amount.

The available NMR data for the mixtures $\mathbf{1 0 / 1 3}$ are provided in the ESI.t

NMR monitoring of the thermal behaviour of $4 \mathrm{~b}$ in the presence of different additives. In the glove box, a solution containing $0.234 \mathrm{~g}(1 \mathrm{mmol})$ of $\mathbf{4 b}$ in $1 \mathrm{~mL}$ of THF was prepared. This was divided into five portions of $0.2 \mathrm{ml}$, and each one was transferred to a different gas-tight NMR tube (PTFE valve), containing a sealed glass capillary with a $\mathrm{PPh}_{3} / \mathrm{C}_{6} \mathrm{D}_{6}$ external reference. One of the tubes was used to prepare a blank (control) sample with no other reagent added. Two samples were treated with, respectively, 2 equiv. $(0.018 \mathrm{~g}, 0.093 \mathrm{mmol})$ and 4 equiv. (0.018 g, $0.093 \mathrm{mmol}$ ) of 4-bromoacetophenone, each dissolved in $0.2 \mathrm{~mL}$ of THF. The remaining two samples were treated with, respectively, 2 equiv. $(8.50 \mu \mathrm{L})$ and 4 equiv. $(17.0 \mu \mathrm{L})$ of methyl acrylate. Subsequently, the total volume of the five samples was adjusted to $0.6 \mathrm{ml}$ with THF. The samples were analysed by ${ }^{31} \mathrm{P}\left\{{ }^{1} \mathrm{H}\right\}$ NMR and then they were heated at $40{ }^{\circ} \mathrm{C}$ in an oil bath, removing all of them and bringing them back simultaneously to record their spectra at predefined time lapses: $15,45,105,225$, and $345 \mathrm{~min}$. The decay of the ${ }^{31} \mathrm{P}$ NMR signal of $\mathbf{4 b}$ was fitted to a first-order plot, from which the half-live of the complex in each sample was computed.

NMR studies on the reversible deprotonation of $\left[\mathrm{Ni}\left(\mathrm{CH}_{2} \mathrm{SiMe}_{3}\right)\right.$ (py)(Lb) $]^{+}[\mathrm{OTf}]^{-}(6 \mathrm{~b})$ with different bases

General procedure. In the glove box, a scintillation vial charged with $0.030 \mathrm{~g}(35 \mu \mathrm{mol})$ of complex $\mathbf{6 b}$ was dissolved in $1 \mathrm{~mL}$ of THF. When the base to be tested was soluble in 
THF, an exact equimolar amount was added to the mixture (triethylamine $(5 \mu \mathrm{L})$, diisopropylethylamine $(6 \mu \mathrm{L})$, proton sponge $(7.5 \mathrm{mg})$, DBU $(5 \mu \mathrm{l})$, or $\left.\mathrm{K}^{t} \mathrm{BuO}(3.9 \mathrm{mg})\right)$. In the case of the partially or totally insoluble bases $\mathrm{Cs}_{2} \mathrm{CO}_{3}$ and $\mathrm{NaH}$, a 10 -fold excess of the base was used and the mixture was stirred for $18 \mathrm{~h}$. The resulting solutions were transferred to a gas-tight NMR tube, provided with an external reference $\left(\mathrm{PPh}_{3} / \mathrm{C}_{6} \mathrm{D}_{6}\right)$ sealed in a glass capillary. Triethylamine, diisopropylethylamine, and proton sponge failed to induce any change on the ${ }^{31} \mathrm{P}\left\{{ }^{1} \mathrm{H}\right\}$ spectrum of $\mathbf{6 b}$, even after $18 \mathrm{~h}$ at room temperature. The samples containing triethylamine and diisopropylethylamine were taken to the glove box and an additional amount (4 equiv.) of the corresponding base was added. Although some color darkening was observed, their spectra showed no noticeable changes. The sample containing the proton sponge was heated at $60^{\circ} \mathrm{C}$ for $1 \mathrm{~h}$, but its ${ }^{31} \mathrm{P}\left\{{ }^{1} \mathrm{H}\right\}$ spectrum remained unaltered. In the case of DBU, an immediate change to orange occurred on mixing, the ${ }^{31} \mathrm{P}\left\{{ }^{1} \mathrm{H}\right\}$ signal of $\mathbf{6} \mathbf{b}$ was replaced with a broad resonance in the position expected for $\mathbf{3 b}$, albeit with lower intensity than expected. The sample remained stable at room temperature for $18 \mathrm{~h}$, then it was taken to the box and an extra amount of DBU (4 equiv.) was added, prior to recording its ${ }^{31} \mathrm{P}\left\{{ }^{1} \mathrm{H}\right\}$ spectrum. The reactions with $\mathrm{Cs}_{2} \mathrm{CO}_{3}, \mathrm{~K}^{t} \mathrm{BuO}$ or $\mathrm{NaH}$ caused a rapid color change to orange, associated with the deprotonation of $\mathbf{6 b}$, as confirmed by the ${ }^{31} \mathrm{P}\left\{{ }^{1} \mathrm{H}\right\}$ spectra of the mixtures, which showed a single resonance for $\mathbf{3 b}$. The experiment was repeated with $\mathrm{NaH}$, and after confirming that full conversion had taken place, the sample was brought back to the box, any excess of $\mathrm{NaH}$ or solid salts was filtered out using a $0.45 \mu \mathrm{m}$ PTFE filter and an equimolar amount of triflic acid was added, resulting in the clean regeneration of the ${ }^{31} \mathrm{P}$ signal of $\mathbf{6 b}$. The same operation was repeated with the $\mathrm{K}^{t} \mathrm{BuO}$ sample, with an identical result.

\section{Deprotonation of complex 7a with $\mathrm{NaH}$ or $\mathrm{NaOH}$}

Syntheses of $\left[\mathrm{Ni}\left(p-\mathrm{C}_{6} \mathrm{H}_{4} \mathrm{COMe}\right)(\mathrm{OH})\left(\mathrm{L}^{\prime} \mathrm{a}\right)\right]^{-} \mathrm{Na}^{+}$16. In the glove box, $\mathrm{NaH}(0.037 \mathrm{~g}, 1.53 \mathrm{mmol})$ was placed in a $7 \mathrm{~mL}$ scintillation vial with a small magnetic sitting bar. Then, a solution of complex 7a $(0.100 \mathrm{~g}, 0.153 \mathrm{mmol})$ in $4.5 \mathrm{~mL}$ of THF was added dropwise to the $\mathrm{NaH}$ reagent at room temperature. The reaction mixture was stirred for $1 \mathrm{~h}$, during which time its colour changed from yellow to dark orange. Once the prescribed time was over, the mixture was filtered through a PTFE $0.45 \mu \mathrm{M}$ HPLC syringe filter and dried under reduced pressure to obtain a dark orange oily residue. This was washed with $n$-hexane $(3 \mathrm{~mL})$, and dried under vacuum giving a fine yellow powder. The latter was purified by subsequent crystallization by slow diffusion of a hexane layer into THF solution in the box freezer $\left(-25{ }^{\circ} \mathrm{C}\right)$. Compound (16) was obtained as clear orange crystals in $33 \%$ yield $(0.030 \mathrm{~g}, 0.048 \mathrm{mmol})$. X-ray quality crystals were obtained by slow diffusion of hexane into a $\mathrm{THF} / \mathrm{Et}_{2} \mathrm{O}$ mixture of $\mathbf{1 6}$. The same product 16 was obtained in $97 \%$ yield $(0.091 \mathrm{~g}, 0.15 \mathrm{mmol})$ using finely ground $\mathrm{NaOH}$ $(0.061 \mathrm{~g}, 1.53 \mathrm{mmol})$ instead of $\mathrm{NaH}$, and following exactly the same protocol. In this case, the colour of the reaction mixture remained clear orange, no darkening was observed as with NaH. ${ }^{31} \mathrm{P}\left\{{ }^{1} \mathrm{H}\right\}$ NMR (161.9 MHz, $25{ }^{\circ} \mathrm{C}$, THF- $\left.d_{8}\right): \delta 47.7$ (s). ${ }^{1} \mathrm{H}$ NMR (400 MHz, $25{ }^{\circ} \mathrm{C}$, THF- $\left.d_{8}\right): \delta-2.79(\mathrm{~s}, 1 \mathrm{H},-\mathrm{OH}), 0.96$ $\left(\mathrm{d}, 6 \mathrm{H},{ }^{3} J_{\mathrm{HH}}=7.0 \mathrm{~Hz}, \operatorname{ArCHMeMe}\right), 1.11\left(\mathrm{dd}, 6 \mathrm{H},{ }^{3} J_{\mathrm{HP}}=\right.$ $\left.15.1 \mathrm{~Hz},{ }^{3} J_{\mathrm{HH}}=7.3 \mathrm{~Hz}, \mathrm{P}-\mathrm{CHMeMe}\right), 1.29\left(\mathrm{dd}, 6 \mathrm{H},{ }^{3} J_{\mathrm{HP}}=\right.$ $\left.13.3 \mathrm{~Hz},{ }^{3} J_{\mathrm{HH}}=7.0 \mathrm{~Hz}, \mathrm{P}-\mathrm{CHMeMe}\right), 1.55\left(\mathrm{~d}, 6 \mathrm{H},{ }^{3} J_{\mathrm{HH}}=6.8 \mathrm{~Hz}\right.$, ArCHMeMe), 1.82 (d sept, $2 \mathrm{H},{ }^{2} J_{\mathrm{HP}}=9.2 \mathrm{~Hz},{ }^{3} J_{\mathrm{HH}}=6.9 \mathrm{~Hz}$, P-CHMe $\mathrm{M}_{2}$ ), $2.33\left(\mathrm{~s}, 3 \mathrm{H},-\mathrm{COCH}_{3}\right), 3.03\left(\mathrm{~d}, 1 \mathrm{H},{ }^{2} J_{\mathrm{HP}}=1.7 \mathrm{~Hz}\right.$, P-CH), 3.86 (sept, $2 \mathrm{H},{ }^{3} J_{\mathrm{HH}}=7.2 \mathrm{~Hz}, \mathrm{CHMe}$ ), $6.73(\mathrm{~m}, 2 \mathrm{H}$, $m$-N-Ar), 6.75 (m, $1 \mathrm{H}, p$-N-Ar), 6.87 (m, $2 \mathrm{H}, m-\mathrm{Ph}), 6.87$ (m, 1 $\mathrm{H}, p-\mathrm{Ph}), 7.02(\mathrm{~m}, 2 \mathrm{H}, o-\mathrm{Ph}), 7.31\left(\mathrm{~d}, 2 \mathrm{H},{ }^{3} J_{\mathrm{HH}}=8.1 \mathrm{~Hz}\right.$, $m$-Ni-Ar), 7.88 (dd, $2 \mathrm{H},{ }^{4} J_{\mathrm{HP}}=1.1 \mathrm{~Hz},{ }^{3} J_{\mathrm{HH}}=8.1 \mathrm{~Hz}, o-\mathrm{Ni}-\mathrm{Ar}$ ). ${ }^{13} \mathrm{C}\left\{{ }^{1} \mathrm{H}\right\}$ NMR (100.6 MHz, $25{ }^{\circ} \mathrm{C}$, THF- $d_{8}$ ): $\delta 17.7$ (P-CHMeMe), 18.5 (P-CHMeMe), 23.4 (ArCHMeMe), 23.8 (d, ${ }^{1} J_{\mathrm{CP}}=30.3 \mathrm{~Hz}$, $\mathrm{PCHMe}_{2}$ ), 25.8 (ArCHMeMe), $25.8\left(-\mathrm{COCH}_{3}\right), 28.8\left(\mathrm{ArCHMe}_{2}\right)$, 67.9 (hidden under the solvent residual signal, $\mathrm{P}-\mathrm{CH}$ ), 122.7 ( $m$ - $\mathrm{CH}, \mathrm{N}$-Ar), 123.2 ( $p$ - $\mathrm{CH}, \mathrm{N}-\mathrm{Ar}$ ), 123.7 ( $m$ - $\mathrm{CH}, \mathrm{Ni}-\mathrm{Ar}), 126.5$ ( $p$ - $\mathrm{CH}, \mathrm{Ph}), 126.8$ ( $m-\mathrm{CH}, \mathrm{Ph}), 129.3$ (o-CH, Ph), 131.8 ( $p-C_{\mathrm{q}}, \mathrm{Ni}-$ $A r$ ), 139.1 (o-CH, NiAr), 142.7 (d, ${ }^{3} J_{\mathrm{CP}}=16.2 \mathrm{~Hz}$, ipso- $C_{\mathrm{q}}, \mathrm{Ph}$ ), $147.2\left(o-C_{\mathrm{q}}, \mathrm{N}-\mathrm{Ar}\right.$ ), 148.3 (ipso- $C_{\mathrm{q}} \mathrm{N}-A r$ ), 175.8 (d, ${ }^{2} J_{\mathrm{CP}}=22.5 \mathrm{~Hz}$, $=C-\mathrm{N}), 182.4\left(\mathrm{~d},{ }^{2} J_{\mathrm{CP}}=43.0 \mathrm{~Hz}\right.$, ipso- $\left.C_{\mathrm{q}}, \mathrm{Ni}-A r\right), 197.2(-C \mathrm{OMe})$. IR (nujol mull, cm ${ }^{-1}$ ): 3584 (sh, w, (O-H)), 3422 (br, st, (O-H)), 3053 (sh, w, $\nu(\mathrm{C}-\mathrm{H}$ arom.), 1669, $1657(\nu(\mathrm{C}=\mathrm{O}, \nu \mathrm{C}=\mathrm{C})$. Anal. calcd for $\mathrm{C}_{34} \mathrm{H}_{45} \mathrm{NNaNiO}_{2} \mathrm{P}$ : C, 66.68; H, 7.41; N, 2.29. Found: C, 66.93; H, 7.68; N, 1.96 .

\section{Conflicts of interest}

There are no conflicts to declare.

\section{Acknowledgements}

The Spanish Ministries of Economy and Innovation (MINECO) and Ciencia, Innovación y Universidades (MCIU/AEI) and the EU FEDER funds of the European Union supported this work through grants CTQ2015-68978-P and PGC2018-095768-B-I00.

\section{Notes and references}

1 (a) R. Tannert and A. Pfaltz, in Phosphorus(III) Ligands in Homogeneous Catalysis: Design and Synthesis, ed. P. C. Kamer and P. W. N. M. van Leeuwen, Wiley, 2012, ch. 7, pp. 233-286; (b) W.-H. Zhang, S. W. Chen and T. S. A. Hor, Coord. Chem. Rev., 2011, 255, 1991-2024; (c) I. D. Kostas, Curr. Org. Synth., 2008, 5, 227-249.

2 V. Vasilenko, T. Roth, C. K. Blasius, S. N. Intorp, H. Wadepohl and L. Gade, Beilstein J. Org. Chem., 2016, 12, 856-953.

3 (a) F. Speiser, P. Braunstein and L. Saussine, Acc. Chem. Res., 2005, 36, 784-793; (b) A. Ravasio, L. Boggioni and I. Tritto, in Olefin Upgrading Catalysis by Nitrogen-based Metal Complexes I, ed. G. Giambastiani and J. Cámpora, Springer, 2011, ch. 2, pp. 27-118. 
4 S. Wang, W.-H. Sun and C. Redshaw, J. Organomet. Chem., 2014, 751, 717-741.

5 L. K. Johnson, C. M. Killian and M. Brookhart, J. Am. Chem. Soc., 1995, 117, 6414-6415.

6 (a) L. Guo, S. Dai, X. Sui and C. Chen, ACS Catal., 2016, 6, 428-441; (b) S. D. Ittel, L. K. Johnson and M. Brookhart, Chem. Rev., 2000, 1000, 1169-1204.

7 (a) W. Keim, S. Killat, C. F. Nobile, G. P. Suranna, U. Englert, R. Wang, S. Mecking and D. L. Schröder, J. Organomet. Chem., 2002, 662, 150-171; (b) Z. Guan and W. J. Marshall, Organometallics, 2002, 21, 3580-3586; (c) G. Müller, M. Klinga, P. Osswald, M. Leskela and B. Rieger, Z. Naturforsch., 2002, 57b, 803-809.

8 O. Daugulis and M. Brookhart, Organometallics, 2002, 21, 5926-5934.

9 (a) K. S. Coleman, M. L. H. Green, S. I. Pascu, N. H. Rees, A. R. Cowley and L. H. Rees, J. Chem. Soc., Dalton Trans., 2001, 3384-3395; (b) S. I. Pascu, K. S. Coleman, A. R. Cowley, M. L. H. Green and N. H. Rees, New J. Chem., 2005, 29, 385-397.

10 For some relevant reviews on this topic, see: (a) D. Wang, A. B. Weinstein, P. B. White and S. S. Stahl, Chem. Rev., 2018, 118, 2636-2679; (b) J. R. Khusnutdinova and D. Milstein, Angew. Chem., Int. Ed., 2015, 54, 12236-12273; (c) S. Kuwata and T. Ikariya, ChemCatChem, 2014, 50, 14290-14300; (d) A. McSkimming and S. B. Colbran, Chem. Soc. Rev., 2013, 42, 5439-5488; (e) J. I. van de Vlugt, Eur J. Inorg. Chem., 2012, 363-375; (f) J. I. van der Vlugt and J. N. H. Reek, Angew. Chem., Int. Ed., 2009, 48, 8832-8846.

11 For example, see: C. Tian, L. Gong and E. Meggers, Chem. Commun., 2016, 52, 4207-4210, and references therein.

12 (a) T. C. Wambach, J. M. Ahn, B. O. Patrick and M. D. Fryzuk, Organometallics, 2013, 32, 4431-4432; (b) T. C. Wambach and M. D. Fryzuk, Inorg. Chem., 2015, 54, 5888-5896.

13 (a) A. J. Ruddy, C. M. Kelly, S. M. Crawford, C. A. Wheaton, O. L. Sydora, B. L. Small, M. Stradiotto and L. Turculet, Organometallics, 2013, 32, 5185-5188; (b) A. J. Ruddy, O. L. Sydora, B. L. Small, M. Stradiotto and L. Turculet, Chem. - Eur. J., 2014, 20, 13918-13922; (c) C. M. Kelly, D. H. Ess, M. Stradiotto and L. Turculet, Angew. Chem., Int. Ed., 2015, 54, 11498-11504; (d) C. M. Kelly, J. T. Fuller, C. M. Macaulay, R. McDonald, M. J. Ferguson, S. M. Bischof, O. L. Sydora, D. H. Ess, M. Stradiotto and L. Turculet, Angew. Chem., Int. Ed., 2017, 56, 6312-6316.

14 (a) L. Ortiz de la Tabla, I. Matas, P. Palma, E. Álvarez and J. Cámpora, Organometallics, 2012, 31, 1006-1016; (b) L. Ortiz de la Tabla, I. Matas, E. Álvarez, P. Palma and J. Cámpora, Dalton Trans., 2012, 41, 14524-14539.

15 (a) S. Mecking, Coord. Chem. Rev., 2000, 203, 325-351; (b) J. Cámpora, in Comprehensive Organometallic Chemistry III, ed. D. M. P. Mingos, R. H. Crabtree and A. Canty, Elsevier, 2007, vol. 8.

16 J. Cámpora, M. M. Conejo, K. Mereiter, P. Palma, C. Pérez, M. L. Reyes and C. Ruiz, J. Organomet. Chem., 2003, 683, 220-239.
17 (a) E. Carmona, F. González, M. L. Poveda, J. L. Atwood and R. D. Rogers, J. Chem. Soc., Dalton Trans., 1981, 777-782; (b) Y. Pan and G. B. Young, J. Organomet. Chem., 1999, 577, 257-264.

18 D. A. Smith, A. S. Batsanov, K. Costuas, R. Edge, D. C. Apperley, D. Collison, J. F. Halet, J. A. K. Howard and P. W. Dyer, Angew. Chem., Int. Ed., 2010, 49, 70407044.

19 (a) P.-L. Yi and L.-C. Liang, Inorg. Chem., 2008, 47, 749-758; (b) P. Braunstein, J. Pietsch, Y. Chauvin, S. Mercier, L. Saussine, A. DeCian and J. Fischer, J. Chem. Soc., Dalton Trans., 1996, 3571-3574.

20 K. R. Reddy, K. Surekha, G. H. Lee, S. M. Peng and S. T. Liu, Organometallics, 2000, 19, 2637-2639.

21 (a) B. Crociani, S. Antonaroli, V. Beghetto, U. Matteoli and A. Scrivanti, Dalton Trans., 2003, 2194-2202; (b) B. Crociani, S. Antonaroli, L. Canovese, P. Uguagliati and F. Visentin, Eur. J. Inorg. Chem., 2004, 732-742.

22 (a) B. P. Fors, D. A. Watson, M. R. Briscoe and S. L. Buchwald, J. Am. Chem. Soc., 2008, 130, 13552-13554; (b) A. G. Sergeev, T. Schulz, C. Torborg, A. Spannenberg, H. Neumann and M. Beller, Angew. Chem., Int. Ed., 2009, 48, 7595-7599.

23 T. L. Andersen, S. Kramer, J. Overgaard and T. Skrydstrup, Organometallics, 2017, 36, 2058-2066.

24 (a) F. Ozawa, M. Fujimori, T. Yamamoto and A. Yamamoto, Organometallics, 1986, 5, 2144-2149; (b) F. Ozawa, T. Hidaka, T. Yamamoto and A. Yamamoto, J. Organomet. Chem., 1987, 330, 253-263.

25 (a) L. A. Casado, J. A. Casares and P. Espinet, Organometallics, 1997, 16, 5730-5736; (b) D. J. Cárdenas, B. Martín-Matute and A. M. Echavarren, J. Am. Chem. Soc., 2006, 128, 5033-5040; (c) G. Maestri, E. Motti, N. Della Ca, M. Malacria, E. Derat and M. Catellani, J. Am. Chem. Soc., 2011, 133, 8574-8585; (d) Y. Tan, F. Barrios-Landeros and J. F. Hartwig, J. Am. Chem. Soc., 2012, 134, 3683-3686; (e) D. Wang, Y. Izawa and S. S. Stahl, J. Am. Chem. Soc., 2014, 136, 9914-9917.

26 (a) J. F. Hartwig, Organotransition Metal Chemistry. From Bonding to Catalysis, University Science Books, Sausalito, California, 2010; (b) L. Estévez, L. W. Tuxworth, J.-M. Sotirpoulos, P. W. Dyer and K. Miqueau, Dalton Trans., 2014, 43, 11165-11179; (c) T. Yamamoto, M. Abla and Y. Murakami, Bull. Chem. Soc. Jpn., 2002, 75, 19972009.

27 (a) A. Kutt, S. Selberg, I. Kaljurand, S. Tshepelvitsh, A. Heering, A. Darnell, K. Kaupmees, M. Piirsalu and I. Leito, Tetrahedron Lett., 2018, 59, 3738-3748; (b) B. G. Cox, Acids and Bases: Solvent Effects on Acid-Base Strength, Oxford University Press, Oxford, 2013; (c) F. G. Bordwell, Acc. Chem. Res., 1988, 21, 456-463.

28 (a) H. Hoberg, Y. Peres, C. Kruger and Y. H. Tsay, Angew. Chem., Int. Ed., 1987, 26, 771-773; (b) J. Langer, H. Görls and D. Walther, Polyhedron, 2012, 32, 60-67; (c) R. R. A. Freund, H. Görls and J. Langer, Dalton Trans., 2014, 37, 13988-14000. 
29 (a) J. Cámpora, P. Palma, D. del Río and E. Álvarez, Organometallics, 2004, 23, 1652-1655; (b) J. Cámpora, I. Matas, P. Palma, C. Graiff and A. Tiripicchio, Organometallics, 2005, 24, 2827-2830; (c) D. Adhikari, S. Mossin, F. Basuli, B. R. Dible, M. Chipara, H. Fan, J. C. Huffman, K. Meyer and D. J. Mindiola, Inorg. Chem., 2008, 47, 10479-10490; (d) M. K. Samantaray, M. Shaikh and
P. Ghosh, Organometallics, 2009, 28, 2267-2275; (e) D. PowellJia, J. W. Ziller, A. G. DiPasquale, A. L. Rheingold and A. S. Borovik, Dalton Trans., 2009, 2986-2992; (f) A. Castonguay, A. L. Beauchamp and D. Zargarian, Inorg. Chem., 2009, 49, 3177-3184; (g) D. Huang and R. H. Holm, J. Am. Chem. Soc., 2010, 132, 4693-4701; (h) K. L. Jonasson, A. H. Mousa and O. F. Wendt, Polyhedron, 2018, 143, 132-137. 